\title{
Contrasting Eastern-Pacific and Central-Pacific Types of ENSO
}

\author{
HSUN-YING KAO AND JIN-YI YU \\ Department of Earth System Science, University of California, Irvine, Irvine, California
}

(Manuscript received 31 October 2007, in final form 25 June 2008)

\begin{abstract}
Surface observations and subsurface ocean assimilation datasets are examined to contrast two distinct types of El Niño-Southern Oscillation (ENSO) in the tropical Pacific: an eastern-Pacific (EP) type and a central-Pacific (CP) type. An analysis method combining empirical orthogonal function (EOF) analysis and linear regression is used to separate these two types. Correlation and composite analyses based on the principal components of the EOF were performed to examine the structure, evolution, and teleconnection of these two ENSO types. The EP type of ENSO is found to have its SST anomaly center located in the eastern equatorial Pacific attached to the coast of South America. This type of ENSO is associated with basinwide thermocline and surface wind variations and shows a strong teleconnection with the tropical Indian Ocean. In contrast, the CP type of ENSO has most of its surface wind, SST, and subsurface anomalies confined in the central Pacific and tends to onset, develop, and decay in situ. This type of ENSO appears less related to the thermocline variations and may be influenced more by atmospheric forcing. It has a stronger teleconnection with the southern Indian Ocean. Phase-reversal signatures can be identified in the anomaly evolutions of the EP-ENSO but not for the CP-ENSO. This implies that the CP-ENSO may occur more as events or epochs than as a cycle. The EP-ENSO has experienced a stronger interdecadal change with the dominant period of its SST anomalies shifted from 2 to $4 \mathrm{yr}$ near 1976/77, while the dominant period for the CP-ENSO stayed near the 2-yr band. The different onset times of these two types of ENSO imply that the difference between the EP and CP types of ENSO could be caused by the timing of the mechanisms that trigger the ENSO events.
\end{abstract}

\section{Introduction}

El Niño-Southern Oscillation (ENSO) is characterized by interannual sea surface temperature (SST) variations in the eastern-to-central equatorial Pacific. The canonical ENSO event portrayed by Rasmusson and Carpenter (1982) typically develops from the South American coast and propagates westward across the equatorial Pacific. It has been noticed that ENSO SST anomalies could also start from the central equatorial Pacific and spread toward the eastern Pacific (e.g., Wang 1995). This led to the suggestion that there may be more than one type of ENSO in the tropical Pacific, and the changes of the propagation direction may be a result of the alternation of different types of ENSO dynamics, such as the slow-SST type (Neelin 1991; Jin and Neelin 1993a,b) and the delayed-oscillator type

Corresponding author address: Dr. Jin-Yi Yu, Department of Earth System Science, University of California, Irvine, Irvine, CA 92697-3100.

E-mail: jyyu@uci.edu
(Schopf and Suarez 1988; Suarez and Schopf 1988; Battisti and Hirst 1989). Efforts were made to examine different types of ENSO in the tropical Pacific. ENSO events were usually classified according to their periodicity, propagation direction, onset time, or the associated zonal SST structure (e.g., Yasunari 1985; Fu et al. 1986; Barnett et al. 1991; Enfield and Cid 1991; Xu and Chan 2001). Various numbers of ENSO types were identified in those studies. However, it appears that the shift of the SST anomaly center between the eastern and central equatorial Pacific is a common contrasting feature between/among these various types of ENSO. For example, Fu et al. (1986) noticed that El Niño SST anomalies show two major patterns: one with an anomalous warming center in the eastern Pacific and the other in the central Pacific. In another example, Xu and Chan (2001) categorized El Niño events according to their onset time and concluded that there are two types of El Niño events: one onsets in spring and the other in summer. Although not emphasized by the authors, it is noticed from their results that the composite SST anomalies concentrate in the eastern equatorial 
Pacific for the spring-onset type El Niño but in the central Pacific for the summer-onset type El Niño.

Trenberth and Stepaniak (2001) were among the first to recognize that the different characters and evolutions of El Niño events could not be fully accounted for without considering the SST contrast between the eastern and central equatorial Pacific. They used two ENSO SST indices to characterize ENSO evolutions: a Niño-3.4 $\left(5^{\circ} \mathrm{S}-5^{\circ} \mathrm{N}, 170^{\circ} \mathrm{W}-120^{\circ} \mathrm{W}\right) \mathrm{SST}$ index to represent the averaged SST anomalies in the eastern-tocentral Pacific and a trans-Niño index (TNI) to represent the gradient of ENSO SST anomalies between the eastern and central Pacific. The TNI is defined as the difference between the normalized Niño- $1+2\left(10^{\circ} \mathrm{S}-0^{\circ}\right.$, $\left.80^{\circ}-90^{\circ} \mathrm{W}\right)$ and Niño- $4\left(5^{\circ} \mathrm{S}-5^{\circ} \mathrm{N}, 160^{\circ} \mathrm{E}-150^{\circ} \mathrm{W}\right)$ SST indices. By analyzing the lead-lag correlation between Niño-3.4 and TNI, they identified the ENSO evolutions in the past hundred years, including a shift in 1976/77. Trenberth and Smith (2006) noticed that leading variability modes of vertical temperature structure in the atmosphere are associated with different "flavors" of El Niño. One of the leading modes is related to an ENSO type with maximum SST anomalies in the tropical eastern Pacific, and another leading mode is related to an ENSO type that has a broad SST anomaly center in the central Pacific. Larkin and Harrison (2005) also noticed that many El Niño events have their SST anomaly centers concentrate near the date line. They named these events "dateline El Niño" and suggested that they should not be treated the same as the "conventional El Niño" because the "dateline El Niño" events have different temperature and precipitation anomalies around the globe. A very recent study by Ashok et al. (2007) further argued that there exists a type of El Niño that is different from the canonical El Niño whose spatial pattern is characterized by out-ofphase SST anomalies between the central Pacific and the eastern and western Pacific along the equator. All these studies indicate that the zonal shift of SST anomaly pattern between the eastern and central equatorial Pacific is one of the most obvious features to separate different types of ENSO.

$\mathrm{Yu}$ and Kao (2007) noticed that all four Niño SST indices in the eastern-to-central Pacific, that is, the Niño1+2, Niño-3 $\left(5^{\circ} \mathrm{S}-5^{\circ} \mathrm{N}, 150^{\circ}-90^{\circ} \mathrm{W}\right)$, Niño-3.4, and Niño-4 indices, have very different decadal changes in their persistence barriers. In their study, the persistence barrier is identified as the calendar month in which the lagged autocorrelation of the SST index drops to a specified small value more quickly than in the other months, meaning that SST indices are least persistent in that particular month of the year. They found that the persistence barriers for central-Pacific SST indices (i.e., the Niño-3.4 and Niño-4 indices) stayed in the boreal spring in the past four decades (1958-2001) while the persistence barriers for eastern-Pacific SST indices (i.e., the Niño1+2 and Niño-3 indices) changed from decade to decade. The different decadal changes in the timing of the persistence barriers imply that ENSO SST evolutions in the central and eastern equatorial Pacific are probably controlled by different physical processes. By analyzing subsurface ocean information, $\mathrm{Yu}$ and $\mathrm{KaO}$ (2007) further found that the decadal change in the persistence barriers of eastern-Pacific SST indices coincided with the decadal change of mean ocean heat content (OHC) in the equatorial Pacific. They postulated that there may be two types of ENSO: 1) an eastern-Pacific (EP) type that is located in the eastern Pacific and whose generation mechanism involves thermocline variations along the equatorial Pacific and 2) a central-Pacific (CP) type that is located in the central tropical Pacific and whose generation is not sensitive to the thermocline variations. Observed ENSO events do exhibit distinct SST patterns that support the existence of the EP and CP types of El Niño. Two examples are shown in Fig. 1: the 1997/98 and 1977/78 El Niño events. For the 1997/98 El Niño (Fig. 1a), its SST anomalies are mostly located in the eastern part of the tropical Pacific extending from the South American coast at around $80^{\circ}$ to $160^{\circ} \mathrm{W}$ and covering the Niño1+2 and Niño-3 regions (see Fig. 1c). For the 1977/78 El Niño (Fig. 1b), its SST anomalies during the peak phase of the event are mostly concentrated in the central equatorial Pacific from $160^{\circ} \mathrm{E}$ to $120^{\circ} \mathrm{W}$, covering the Niño-3.4 and Niño-4 regions (see Fig. 1d).

In this study, we aim to examine these two types of ENSO by contrasting their surface and subsurface structures and evolution, associated atmosphere-ocean coupling, and teleconnection. An analysis method that combines linear regression and empirical orthogonal function (EOF) is used to separate these two types of ENSO from SST observations. This paper is organized as follows: The datasets used in this study are described in section 2. The spatial characteristics of the EP- and CP-ENSO are examined in section 3. Correlation and composite analyses are presented in section 4 to show the temporal evolution of these two types of ENSO. Their phase locking to the seasonal cycle and teleconnections are discussed in section 5. The results are summarized and discussed in section 6.

\section{Datasets}

Four datasets were used in this study. For SST, we used the $1^{\circ} \times 1^{\circ}$ Met Office Hadley Centre Sea Ice and Sea Surface Temperature dataset (HadISST) (Rayner 
(a) Nov 1997 - Jan 1998

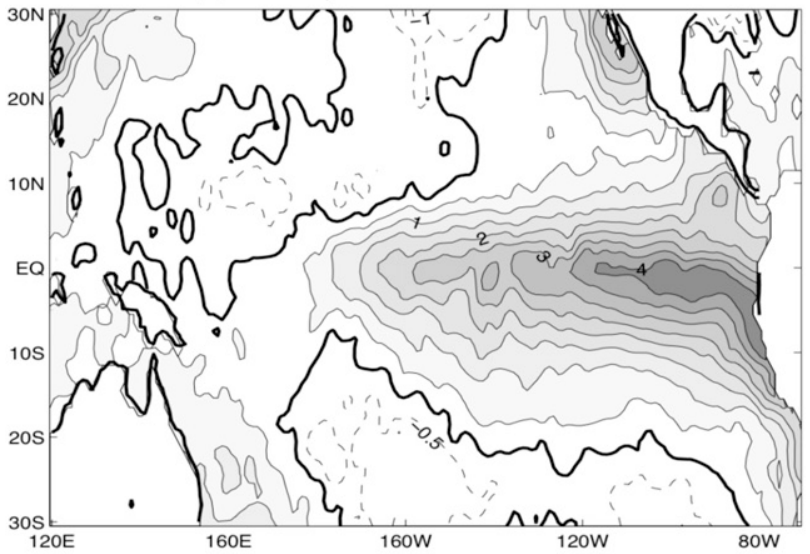

(c) EP type of ENSO

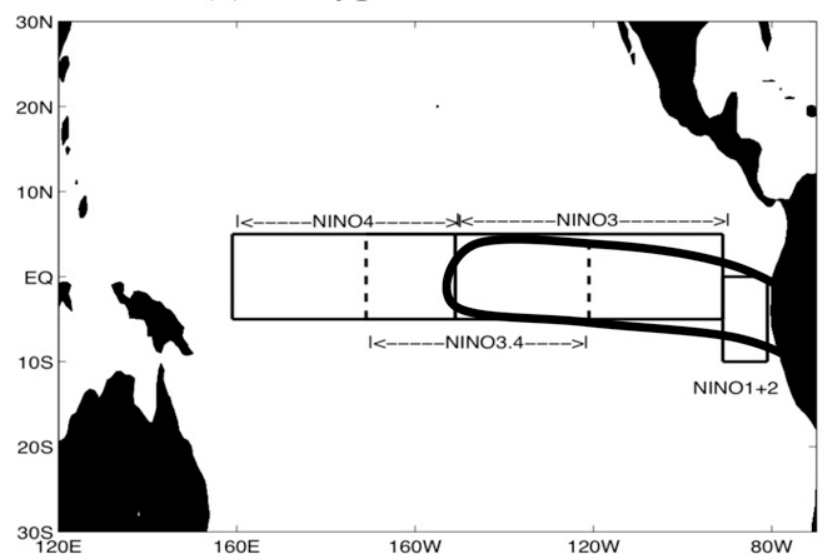

(b) Nov 1977 - Jan 1978

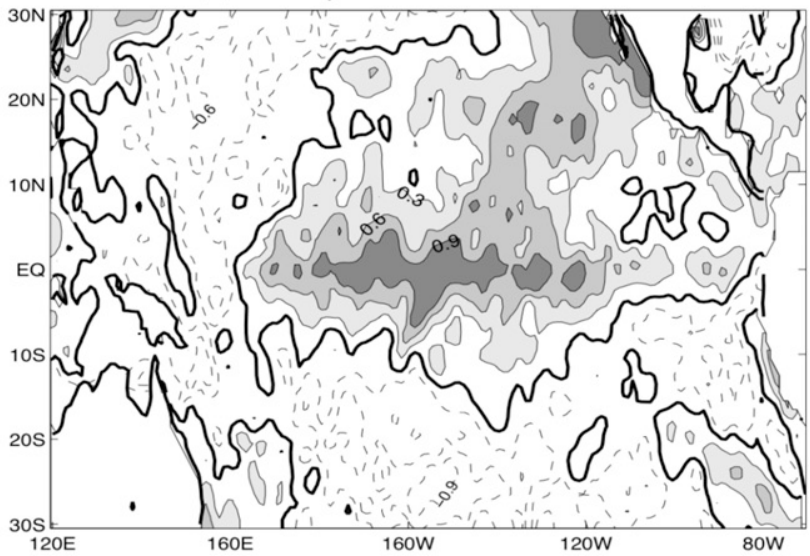

(d) CP type of ENSO

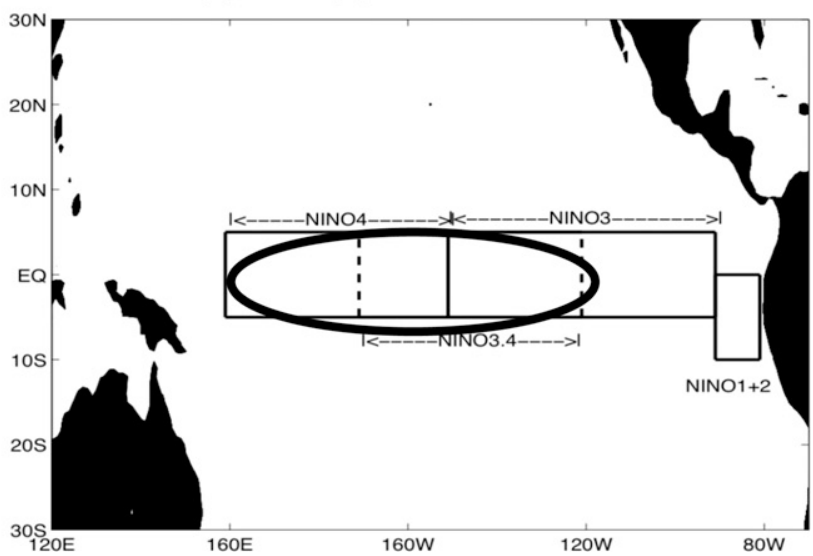

FIG. 1. Examples of the eastern-Pacific and central-Pacific types of ENSO: (a) SST anomalies averaged from November 1997 to January 1998 of the 1997/98 El Niño event and (b) SST anomalies averaged from November 1977 to January 1978 of the $1977 / 78$ El Niño event. The Niño regions covered by each type of ENSO are illustrated (c) for the eastern-Pacific type and (d) for the centralPacific type. The bold contours in (c) and (d) outline the region of SST anomaly patterns of these two ENSO types. Contour intervals are $0.5^{\circ} \mathrm{C}$ for $(\mathrm{a})$ and $0.3^{\circ} \mathrm{C}$ for $(\mathrm{b})$.

et al. 2003). The SST data is available from 1870 until present. Here, we only used the more reliable data after 1950 for analyses. For subsurface ocean temperature information, we used the German Estimating the Circulation and Climate of the Ocean (GECCO) (Kõhl et al. 2006) for the period 1952-2001. The GECCO dataset has 23 levels unevenly divided from 5 to $5450 \mathrm{~m}$ and covers the global oceans from $79.5^{\circ} \mathrm{S}$ to $79.5^{\circ} \mathrm{N}$ with a horizontal resolution of $1^{\circ} \times 1^{\circ}$. The thermocline depth is calculated from this dataset with vertical interpolation of the ocean temperature profile. Surface wind stress information was obtained from National Centers for Environmental Prediction-National Center for Atmospheric Research (NCEP-NCAR) Reanalysis (Kalnay et al. 1996). Monthly means from this reanalysis have a horizontal resolution of $2.5^{\circ} \times 2.5^{\circ}$ and are avail- able from 1948 to 2007. The precipitation data used in this study is from the Global Precipitation Climatology Project (GPCP) (Adler et al. 2003) of which the monthly analysis is available from 1979 to 2007 and has a horizontal resolution of $2.5^{\circ} \times 2.5^{\circ}$. In this paper, anomalies of all variables are defined as the deviations from the mean seasonal cycle.

\section{Spatial characteristics of the EP and CP types of ENSO}

The leading patterns of interannual SST variability in the tropical Pacific have been widely examined with the EOF analysis. As shown in Fig. 2, the first leading EOF mode, which explains $55.7 \%$ of the interannual SST variance, exhibits a typical ENSO SST anomaly pattern 
(a) EOF $1-55.7 \%$

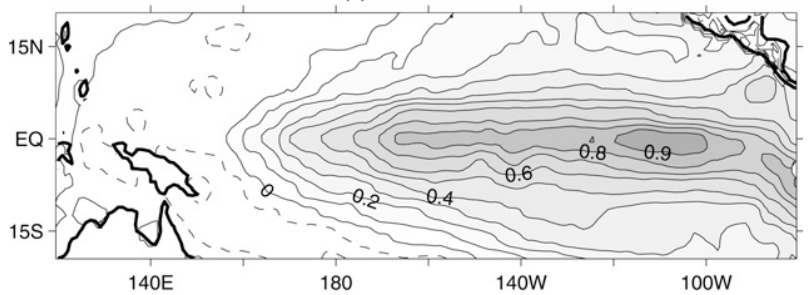

(b) EOF $2-11.1 \%$

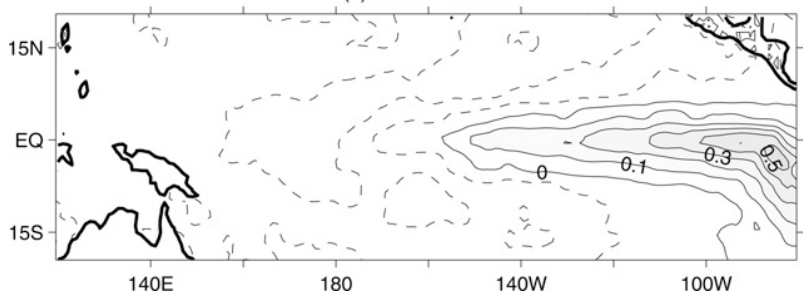

FIG. 2. The (a) first and (b) second leading EOF patterns of interannual SST variability calculated from the HadISST dataset. Contour intervals are 0.1 . The numbers at the top of the panels indicate the percentage of variance explained by each EOF mode.

that centers in the equatorial eastern Pacific and extends into the central Pacific. The second EOF mode, which explains $11.1 \%$ of the variance, is characterized by an out-of-phase relation between SST anomalies in the central Pacific and those in the eastern Pacific. The eastern anomaly center extends from the coast of South America and is confined along the equator, while the anomalies in the central Pacific show a horseshoe pattern that extends toward the subtropics. As indicated in Trenberth and Stepaniak (2001), it requires the combination of theses two leading EOFs to describe different evolutions of ENSO events. Both EP and CP types of ENSO may be described as combinations of these two modes with various phases. Here we use a combined regression-EOF procedure to separate these two types of ENSO. To obtain the CP-ENSO structure with the EOF analysis, we first subtracted the anomalies regressed with the Niño1 +2 index from the original SST anomalies before the EOF analysis is applied. Similarly, we subtracted the SST anomalies regressed with the Niño-4 index from the original SST anomalies before the EOF analysis was applied to identify the leading structure of the EP-ENSO. Figure 3 shows the two leading EOF modes obtained from the aforementioned procedures. The leading EOF mode shown in Fig. 3a represents the EP type of ENSO, which explains 36\% of the residual SST variance after the Niño-4 regression part of the anomalies is removed. This EP type of ENSO is characterized by SST anomalies extending from the South American coast into the central Pacific along the equator. The SST anomalies are mostly contained in the Niño1+2 and Niño-3 regions. This struc-

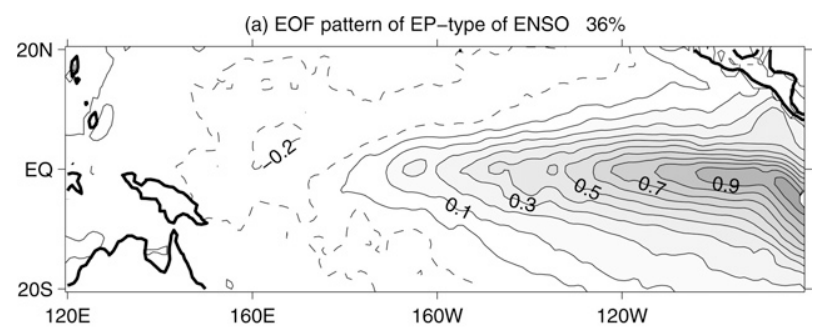

(b) EOF pattern of CP-type of ENSO $38 \%$

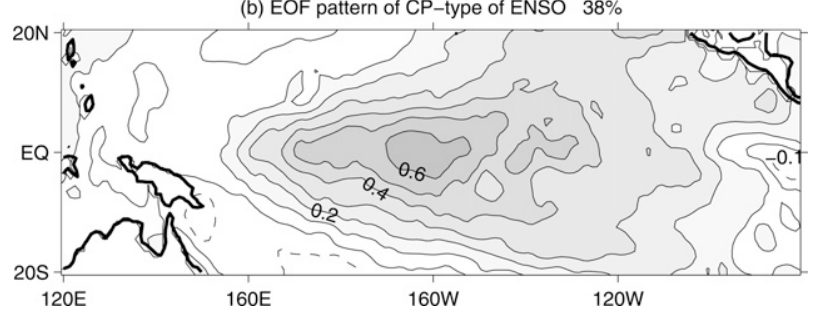

FIG. 3. Leading EOF patterns obtained from a combined EOFregression analysis for (a) the eastern-Pacific type of ENSO and (b) the central-Pacific type of ENSO. Contour intervals are 0.1. The numbers indicated on the top of the panels are the percentage of residual SST variance explained by each EOF mode.

ture is similar to the leading EOF structure obtained from the original SST anomalies (Fig. 2a), but less extending into the central Pacific. Figure $3 \mathrm{~b}$ shows the structure of the CP type of ENSO, which has SST anomalies mostly confined in the central Pacific between $160^{\circ} \mathrm{E}$ and $120^{\circ} \mathrm{W}$, covering the Niño-3.4 and Niño-4 regions. This EOF mode explains $38 \%$ of the residual SST variance. It is interesting to notice that this EOF mode has its SST anomalies extending from the central Pacific toward the northeastern subtropical ocean off Mexico and Central America. This CP-ENSO pattern is very similar to the peak SST anomaly pattern shown in Fig. 1b for the 1977/78 El Niño.

To help reduce the possibility that the SST anomaly patterns are artificial results of the combined regressionEOF method, we also performed a hierarchical cluster analysis to identify leading SST variability patterns. The cluster analysis is a nonlinear composite procedure that continuously merges similar SST maps into clusters. The procedure that we used is similar to that described in Cheng and Wallace (1993). In the first step, Euclidean distance, defined by the root-mean-squared distance, is calculated to measure the pairwise similarity between all SST maps. We then identified the linkages between the maps based on the Ward method (Ward 1963) and grouped the maps into a binary tree (dendrogram). The Ward method merges the pair of clusters with the least sum of squared distance between the maps and the centroids of the respective clusters. Last, a criterion is set up to determine where to cut the dendrogram in order to enlarge the similarity within the 

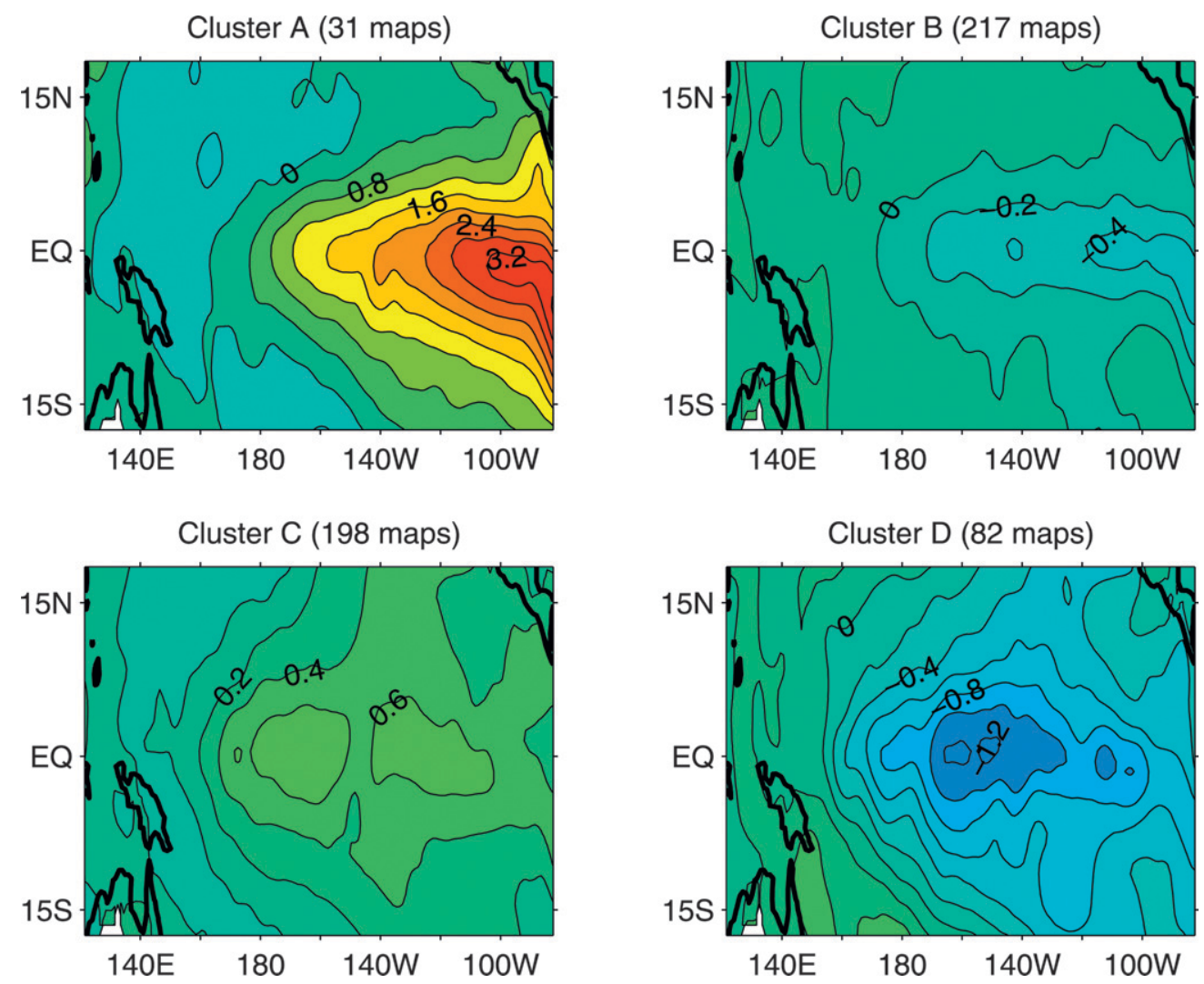

FIG. 4. The final four clusters obtained from the hierarchical cluster analysis. The number of monthly SST maps included in each cluster is indicated at the top of the panel. Contour intervals are $0.4^{\circ} \mathrm{C}$ for cluster A and $0.2^{\circ} \mathrm{C}$ for clusters B-D.

clusters and the dissimilarity between the clusters (Fovell and Fovell 1993; Wolter 1987). We applied the cluster analysis to monthly SST anomalies in the tropical Pacific from 1958 to 2001, for a total of 528 maps. Four final clusters were identified from the analysis and are shown in Fig. 4. The number of monthly maps contained in each of the clusters is also indicated in the figure. Compared to Fig. 3, it is quite obvious that these four clusters have SST anomaly structures similar to the EP- and CP-ENSO patterns obtained from the regression-EOF analysis. For clusters A and B (upper panels in Fig. 4), their SST anomalies are attached to the coast of South America and extend along the equator. For clusters C and D (lower panels in Fig. 4), their anomaly centers are detached from the coasts, centered at about $160^{\circ} \mathrm{W}$ and spreading toward the subtropics in both hemispheres. Clusters A and B resemble the positive and negative phases of the leading EOF for the EPENSO (see Fig. 3a), and clusters C and D resemble the positive and negative phases of the leading EOF for the CP-ENSO (see Fig. 3b). These similarities increase our confidence that the leading EOF patterns that we obtained in Figs. 3 are not artificial results of the analysis method. The rest of the analyses are based on these two leading EOFs.

The principal components (PC) of the two leading EOFs of Fig. 3 are shown in Figs. 5a and 6a. It is noticed that both time series are not symmetric with respect to the zero value. They tend to skew toward either the positive or negative values. The skewness coefficients for the PCs of the EP and CP type of EOFs are 1.18 and -0.45 , respectively. The skewness indicates that the EP type of ENSO tends to appear more often as strong El Niño events than as strong La Niña events. On the other hand, the CP type of ENSO tends to appear more often as strong La Niña events than as strong El Niño events. This reflects the well-known spatial asymmetry between strong El Niño and strong La Niña events (e.g., Monahan 2001; Hsieh 2004; Schopf and Burgman 2006; and several others). Nevertheless, it is necessary to point out that Figs. 5a and 6a show cold EP events and warm CP events also occur often. The EP and CP types of ENSO are not just a reflection of the spatial asymmetry between the strong warm and cold phases of ENSO.

Also shown in Figs. 5 and 6 are the wavelet power spectra of these two PCs. The dash lines in Figs. 5b and 
(a) Time Series of EP Index

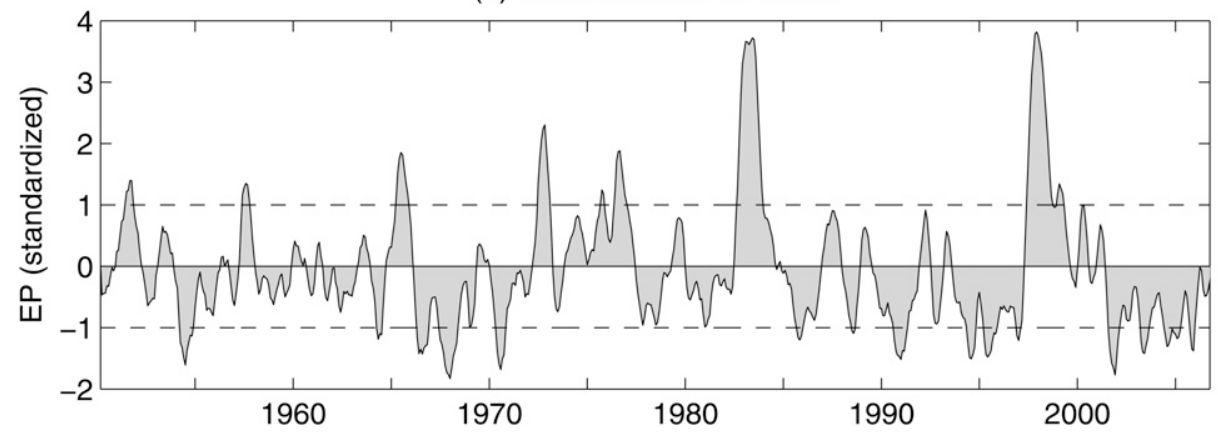

(b) Wavelet Power Spectrum of EP index

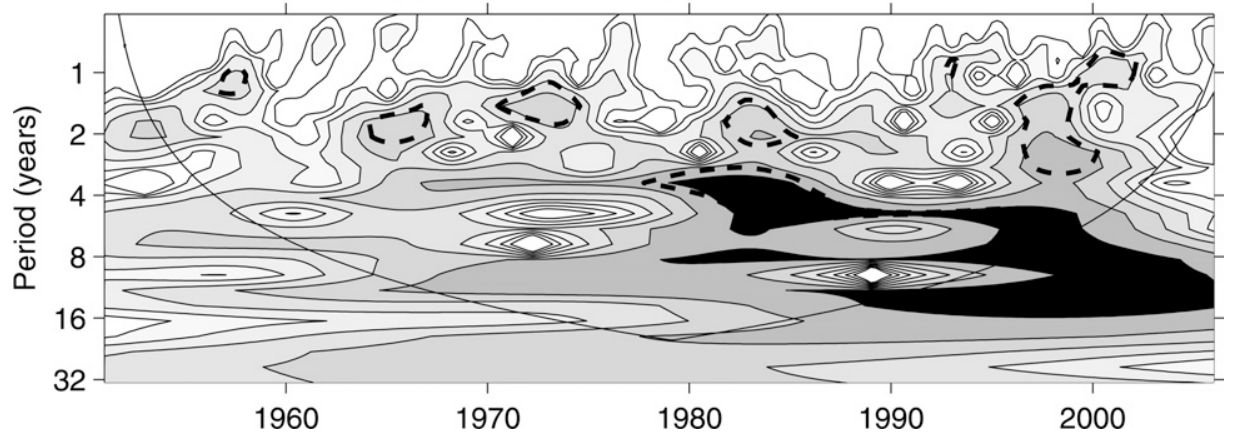

FIG. 5. The (a) time series and (b) wavelet power spectrum of the principal component of the eastern-Pacific type of ENSO. Dashed lines denote the $95 \%$ significant level and the values below the curves are uncertain.

$6 \mathrm{~b}$ denote the $95 \%$ significant level and the values below the curves are uncertain. Figure $5 \mathrm{~b}$ shows that the EP type of ENSO has two dominate periods: one near the 2-yr band and the other near the 4-yr band. The EP-ENSO tends to occur every 2 years before the 1976/ 77 climate shift but every 4 years after the shift. This is consistent with the previous report that ENSO periodicity shifted from two years to about four years around 1976/77 (An and Wang 2000). The skewness coefficient of the principal component of this leading EOF increases from 0.31 for the period $1950-76$ to 1.43 for the period 1977-2006, reflecting the fact that more intense El Niños appear in the eastern Pacific after 1976/77, such as the 1982/83 and 1997/98 El Niños. Figure 6b shows that the principal component of the leading EOF for the CP-ENSO has a significant power around the 2-yr band, which does not shift abruptly around 1976/77. These results suggest that the EP type of ENSO has experienced a stronger decadal/interdecadal change with its periodicity shifted near 1976/77, while the decadal change is relatively small for the CP type of ENSO. It should be noted that the CP-ENSO has a SST anomaly pattern more close to the so-called Pacific decadal oscillation (PDO) (Mantua et al. 1997; Zhang et al. 1997; Zhang et al. 1998). However, the CP events appear to be more sustained, particularly after the late 1980s and have weak decadal wavelet. Instead, the EPENSO has more decadal wavelet, although its spatial pattern is not similar to the PDO pattern. It is unclear to us how to explain this unexpected connection. Maybe the similar horseshoe patterns in interannual and decadal SST variability are not directly related.

\section{Temporal characteristics of the EP and CP types of ENSO}

In addition to the differences in their spatial structure, the EP and CP types of ENSO also show differences in their temporal evolutions. Figure 7 shows the lagged correlation coefficients between the PCs of the two leading EOFs and SST anomalies in the tropical Pacific. The correlation coefficient that passes the $95 \%$ confidence level is 0.29 with a two-tailed Student's $t$ test. With a 0.3 contour interval, all contours shown in the figure are statistically significant. For the EP type of ENSO (Fig. 7a), the SST anomalies emerge from the coast of South America, propagate westward to the central Pacific, and decay off the equator. The peak SST anomalies of this type of ENSO appear near the coasts, accompanied with weaker and opposite anoma- 
(a) Time Series of CP Index

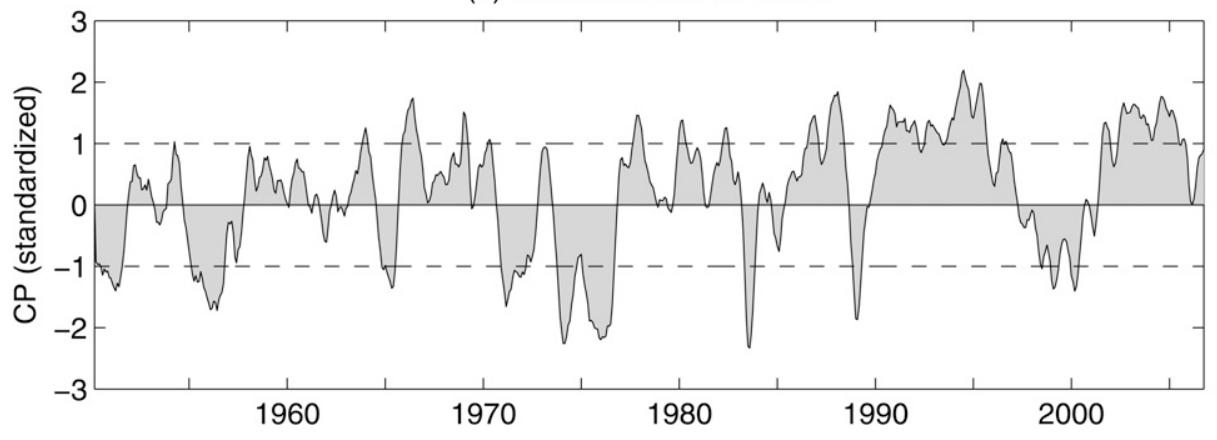

(b) Wavelet Power Spectrum of CP index

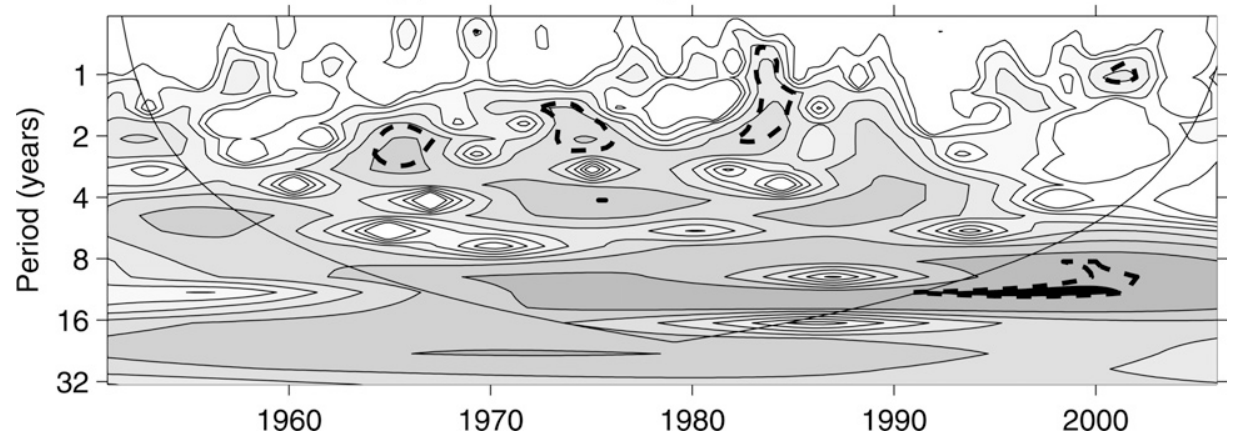

FIG. 6. As in Fig. 5 but for the principal component of the central-Pacific type of ENSO.

lies in the equatorial western Pacific. For the CP type of ENSO (Fig. 7b), SST anomalies first appear around the date line, develop and mature in a V-shaped anomaly structure extending toward the subtropics in both hemispheres (but more into the Northern Hemisphere), and then decay in the equatorial central Pacific. The CPENSO has greater association with SST anomalies in the subtropics than the EP-ENSO. In addition, the propagating feature of the SST anomalies in the CP type of ENSO is weaker and less clear than those of the EP type of ENSO.

We noticed that these two types of ENSO have even larger differences in their subsurface temperature evolutions. Figure 8 shows vertical cross sections of the lagged correlation coefficients between the PCs and the subsurface ocean temperature averaged between $5^{\circ} \mathrm{S}$ and $5^{\circ} \mathrm{N}$ in the Pacific. For the EP type of ENSO (Fig. 8a), large and out-of-phase temperature anomalies in the subsurface ocean appear on both sides of the Pacific basin. Temperature anomalies in the eastern tropical Pacific emerge from the American coasts and then propagate westward on the surface (see the panels from lag -6 months to lag 0 months). At the same time, negative subsurface anomalies accumulated in the western Pacific. After the mature phase of the event, these subsurface temperature anomalies propagate eastward along the thermocline and eventually emerge on the surface of the eastern Pacific and reverse the phase of ENSO. This evolution is similar to that described by the delayed-oscillator theory of ENSO (Schopf and Suarez 1988; Suarez and Schopf 1988; Battisti and Hirst 1989). In contrast, the subsurface temperature evolution of the CP-ENSO (Fig. 8b) does not have a basinwide fluctuation pattern and shows little propagation feature. The initiation, development, and termination of the subsurface temperature anomalies all occur in the central Pacific. The anomalies appear first near the surface and then extend downward to a shallow layer of about $100 \mathrm{~m}$. This depth is well above the local thermocline, which is about $150-200 \mathrm{~m}$ deep, indicating that thermocline variation is not involved in the evolution of the CP type of ENSO. It is important to note that there is no identifiable phase-reversal signal in Fig. 8b, implying that the CP type of ENSO does not behave like a cycle/ oscillation. The CP-ENSO probably occurs as an event that is not driven by thermocline variations, while the EP-ENSO is driven by the delayed-oscillator type of thermocline variation and occurs as a cycle with its warm- and cold-phase events following each other. Discussions of whether ENSO should be viewed as an event or a cycle (e.g., Kessler 2002) might be aided by recognizing that there are two types of ENSO that behave more as an event in one type and more as a cycle in the other. 
(a) Lagged-correlation of PC1 of EP and SST

lag -9
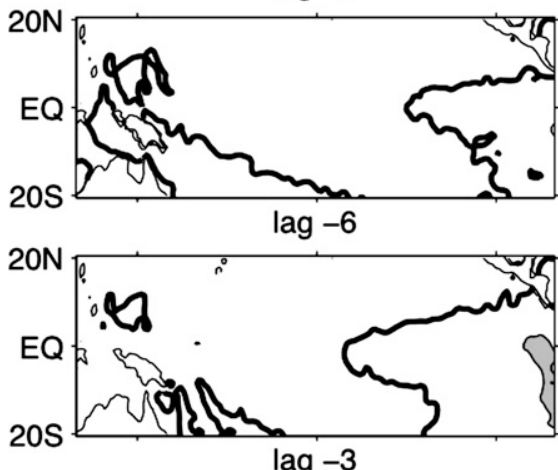

$\operatorname{lag}-3$
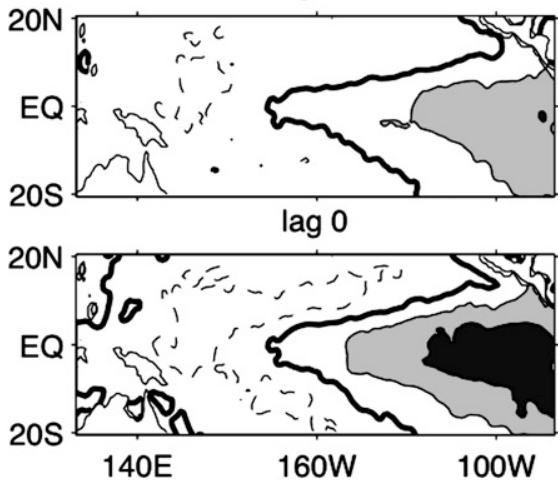

$\operatorname{lag} 3$

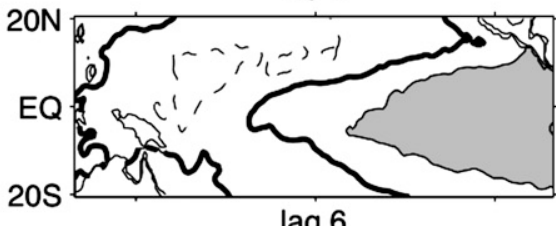

$\operatorname{lag} 6$
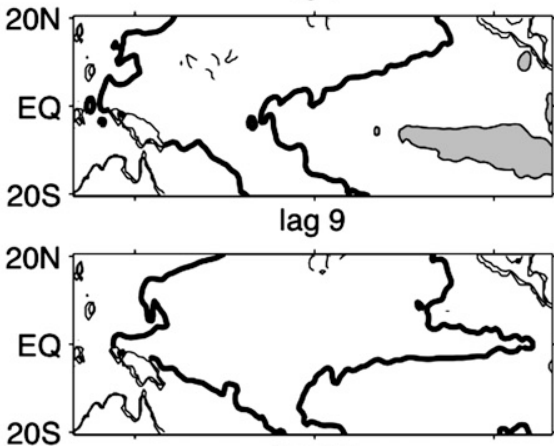

lag 12

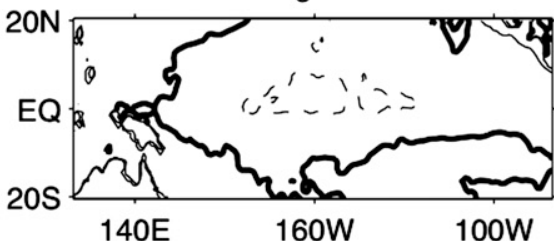

(b) Lagged-correlation of PC1 of CP and SST
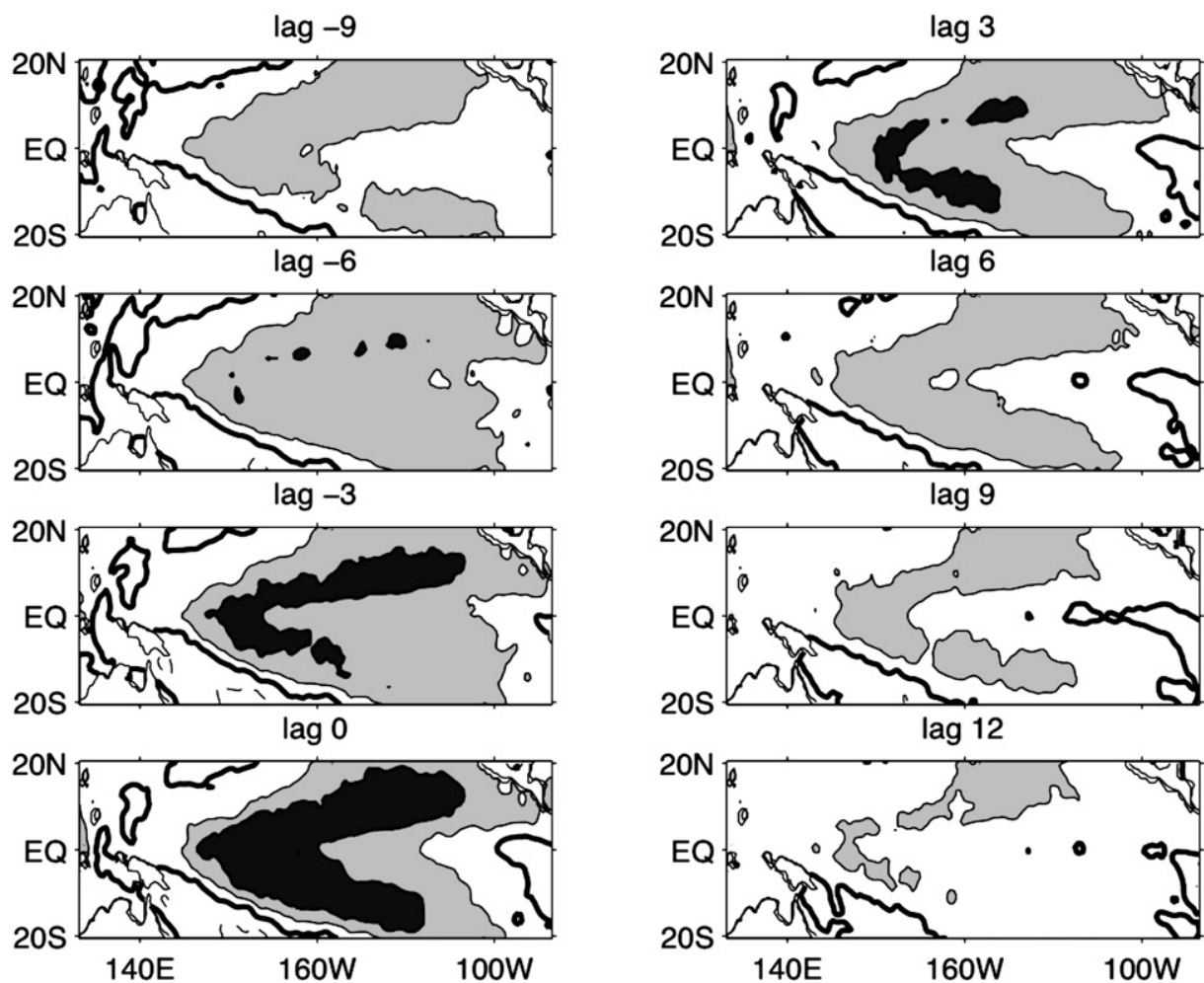

FIG. 7. Lagged-correlation coefficients between the principal components of (a) EP- and (b) CP-EOF with SST anomalies in the tropical Pacific. Contour intervals are 0.3 . The $95 \%$ confidence level is 0.29 with a two-tailed $t$ test. Thick lines denote the zero contour lines. The lag time shown on top of each panel is in unit of months. 
(a) Lagged-correlation of PC1 of EP and subsurface ocean temperature
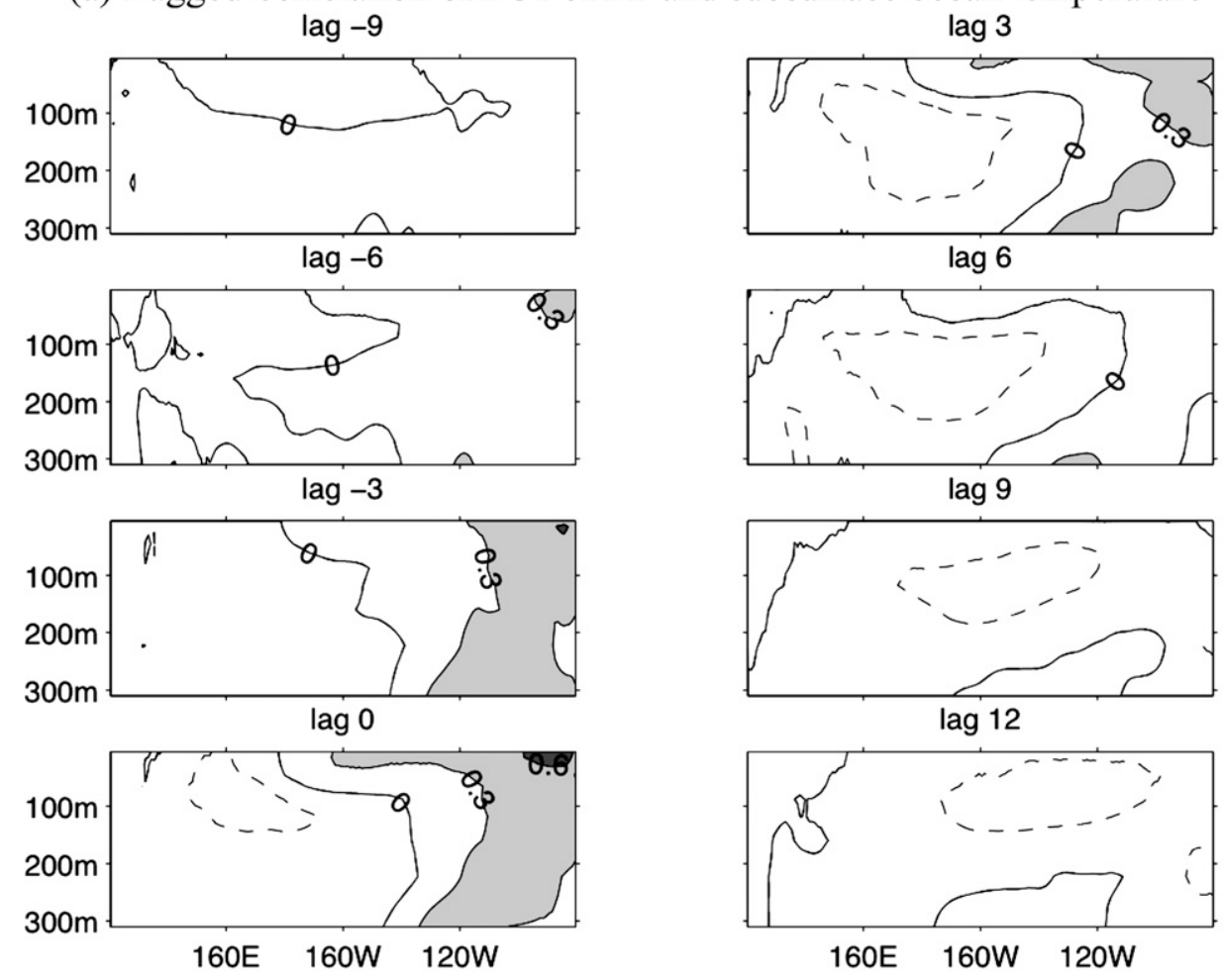

lag 6

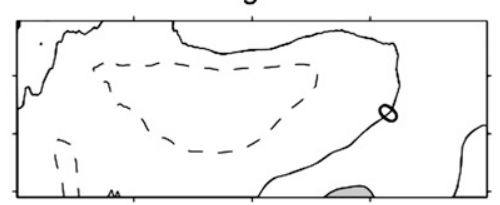

$\operatorname{lag} 9$

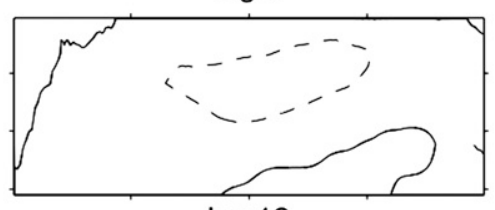

$\operatorname{lag} 12$

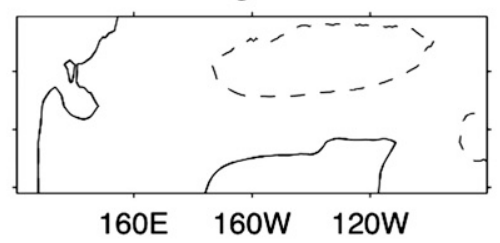

(b) Lagged-correlation of PC1 of CP and subsurface ocean temperature

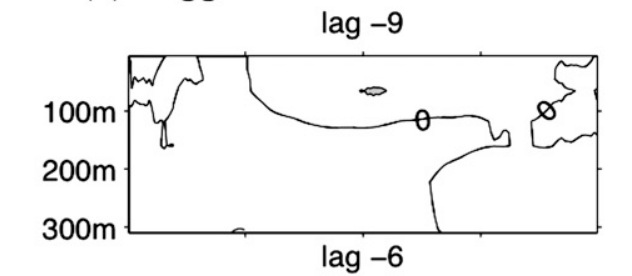

$\operatorname{lag} 3$
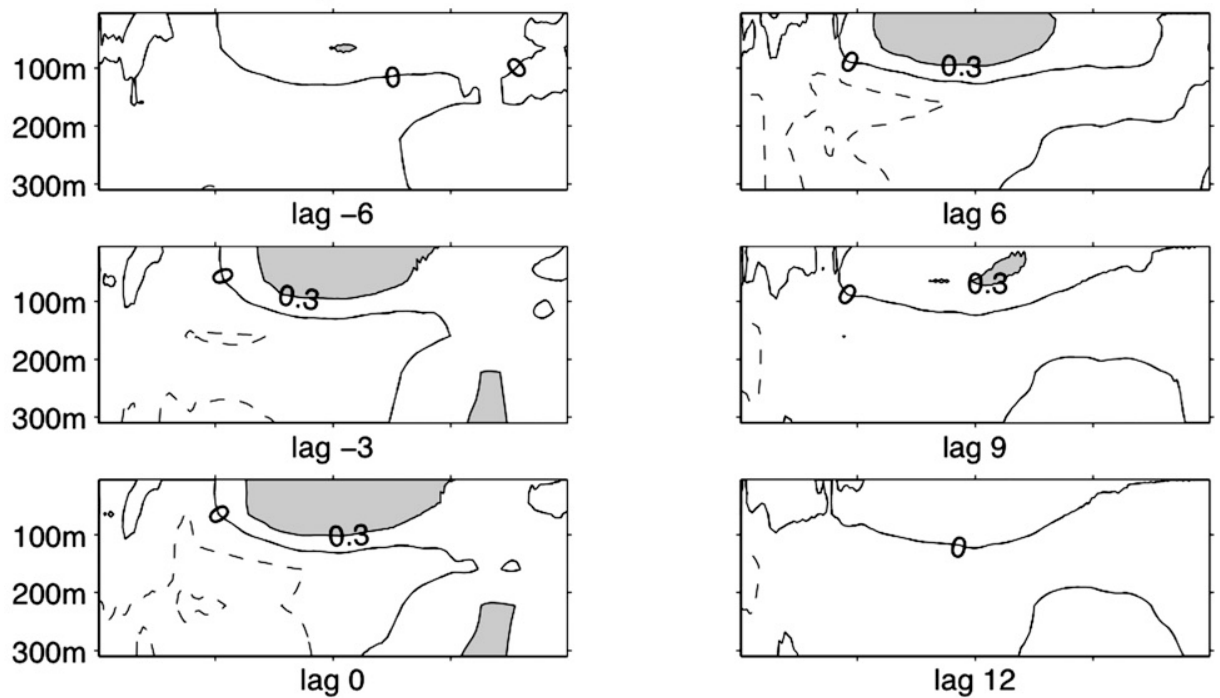

$\operatorname{lag} 12$
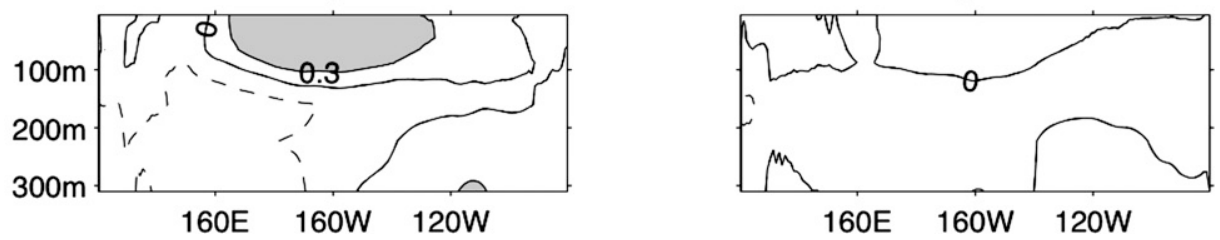

FIG. 8. Lagged-correlation coefficients between the principal components of the (a) EP- and (b) $\mathrm{CP}-\mathrm{EOF}$ and the subsurface ocean temperature anomalies averaged between $5^{\circ} \mathrm{S}$ and $5^{\circ} \mathrm{N}$. Contour intervals are 0.3 . 
(a) EP correlation with SST and surface wind

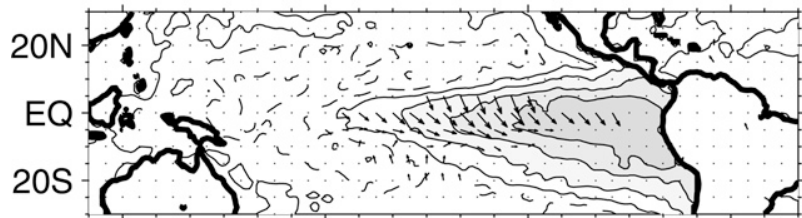

(b) CP correlation with SST and surface wind

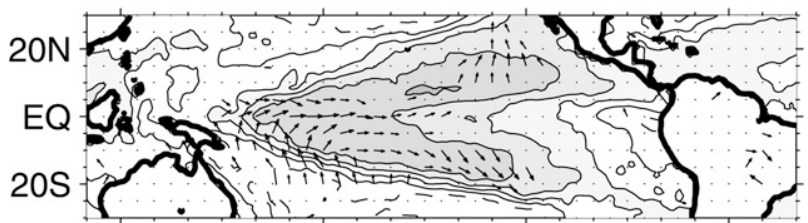

(c) EP correlation with precipitation

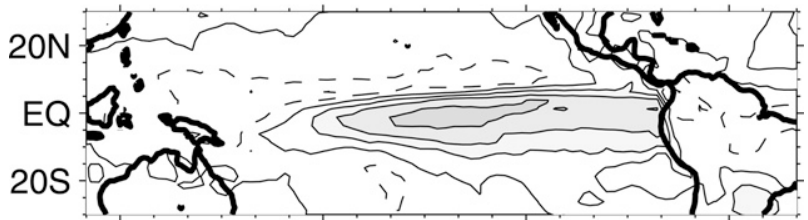

(d) CP correlation with precipitation

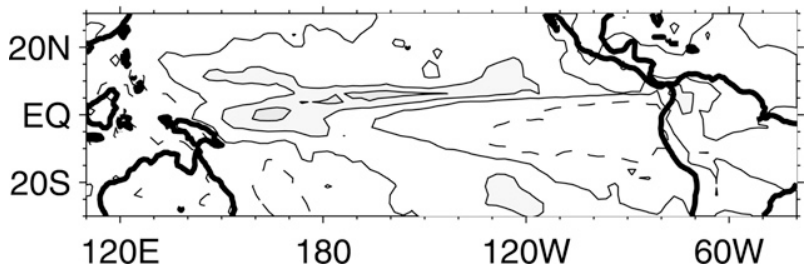

FIG. 9. Lagged-correlation coefficients between the principal components of the EP- and CP-EOFs and surface wind, SST, and precipitation anomalies. (a), (c) The correlations with the EP-EOF; (b), (d) the correlations with the CP-EOF. In (a) and (b) the correlations with the surface wind anomalies are shown as vectors and contours show the correlations with the SST anomalies; correlations with the precipitation anomalies are shown in (c) and (d). Contour intervals are 0.3 for all panels; dashed lines denote negative values. Highlighted vectors indicate the correlation coefficients pass the $95 \%$ significance level estimated by a two-tailed $t$ test.

We further examine the atmosphere-ocean coupling associated with these two types of ENSO. Figures 9a and $9 \mathrm{~b}$ show the correlation coefficients between the PCs and surface wind and SST anomalies. We highlight the coefficients that pass the $95 \%$ significance level estimated by a two-tailed $t$ test. Figure 9a shows that the EP type of ENSO is associated with significant wind stress anomalies covering a large part of the tropical Pacific. On the other hand, surface wind anomalies associated with the CP type of ENSO (Fig. 9b) are limited to the equatorial central-to-western Pacific $\left(130^{\circ} \mathrm{E}-\right.$ $\left.160^{\circ} \mathrm{W}\right)$ and off Australia. The differences in the wind stress patterns further support the suggestion that the EP-ENSO is related to basin-scale coupling processes along the equator, while the CP-ENSO is related to local coupling processes in the central Pacific. Figures $9 \mathrm{c}$ and $9 \mathrm{~d}$ show the lagged-correlation coefficients between the PCs and precipitation anomalies. For EPENSO (Fig. 9c), the precipitation anomalies extend from the equatorial eastern to central Pacific, where the largest SST anomalies are located. There are opposite precipitation anomalies near Indonesia and Amazon regions. The precipitation anomaly pattern associated with this type of ENSO reflects zonal shifts of the Pacific Walker circulation. An EP type of El Niño event shifts the rising branch of the circulation from the far western Pacific to the center-to-eastern Pacific, and vice versa for a La Niña event of the same type. For CP-ENSO (Fig. 9d), the precipitation anomalies are characterized by a dipole pattern within the tropical Pacific with largest anomalies located mainly in the far western and eastern Pacific. It is noticed that the positive and negative anomaly centers of this dipole pattern do not line up in the same latitude. Instead, they tend to be located slightly to the north and to the south of the equator respectively. The anomaly pattern appears related to the meridional shift of the intertropical convergence zone (ITCZ). During the warm phase of CPENSO, the ITCZ intensifies in the equatorial western Pacific and shifts more northward in the eastern Pacific, and vice versa for the cold phase of the CP-ENSO. The impacts of CP-ENSO events on precipitation are much less in Indonesia and are negligible in the Amazon. The different precipitation patterns of these two types of ENSO imply that the associated convective heating locations and the midlatitude teleconnections could be different as well. The impacts of ENSO on the United States, for example, may depend on what type of ENSO event is happening.

The correlation analysis applied so far assumes that the positive and negative phases of the EP- and CPENSO have the same spatial patterns and temporal evolutions, which may not necessary to be the case. We conducted composite analyses to further examine the common and different features between the two phases of the EP- and CP-ENSO. In this section, we use the PC time series to identify the EP and CP types of ENSO for the period 1950-2006. The events whose PC values exceed one standard deviation (the dashed lines in Figs. $5 \mathrm{a}$ and $6 \mathrm{a}$ ) for more than three months are selected for the composite. A total of $7,14,17$, and 10 cases were composite for the positive EP-, negative EP-, positive $\mathrm{CP}-$, and negative CP-ENSO, respectively. The composite is produced according to the peak month of the selected events. Figure 10 shows the composite SST anomalies for the positive (warm) and negative (cold) EP- and CP-ENSO. Figures 10a and 10b show that the composite SST anomalies for EP-El Niño and EP-La 
(a) El Niño
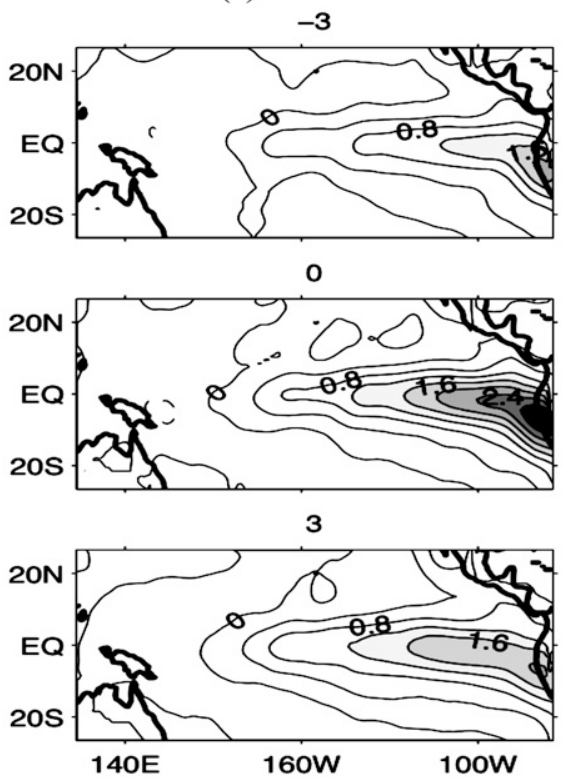

(b) La Niña

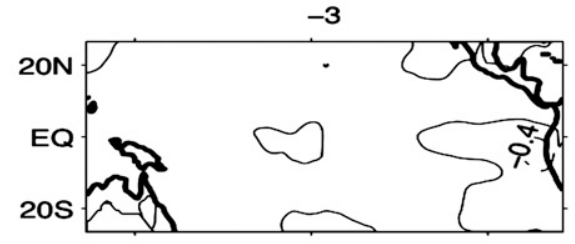

0
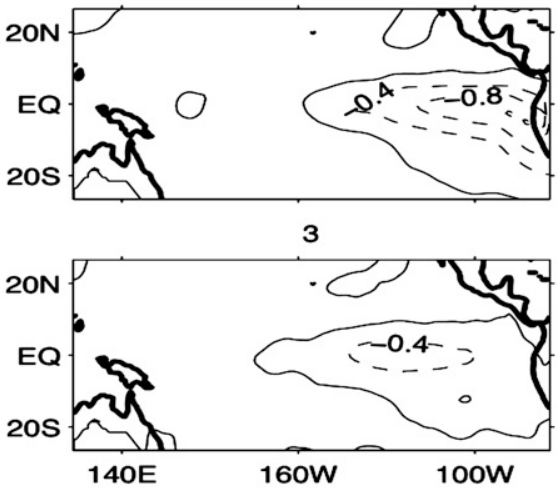

(c) El Niño

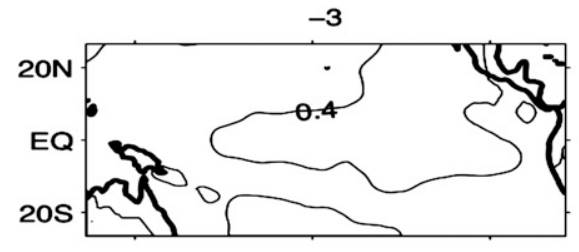

0

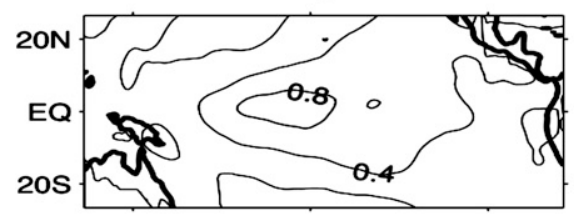

3

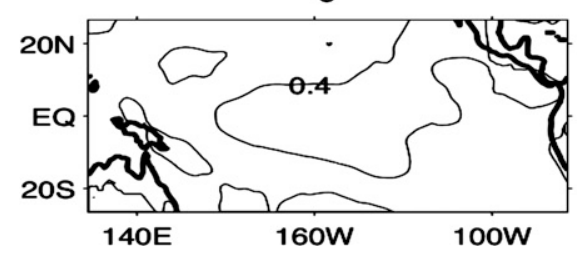

(d) La Niña

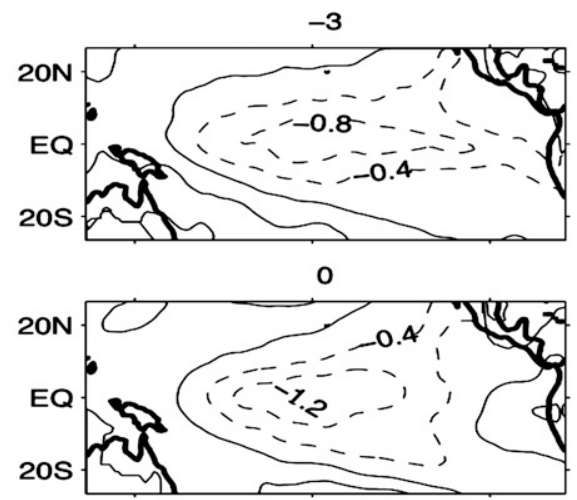

3

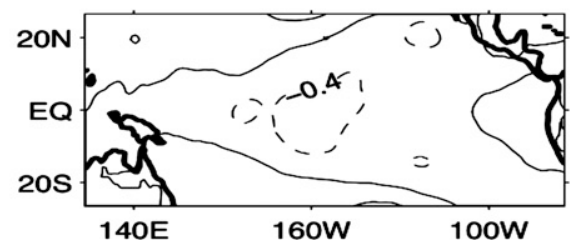

FIG. 10. Composite SST anomalies for (a) EP-El Niño, (b) EP-La Niña, (c) CP-El Niño, and (d) $\mathrm{CP}-\mathrm{La}$ Niña. Contour intervals are $0.4^{\circ} \mathrm{C}$; negative values are dashed. The lag month referenced to the peak-intensity month is labeled above each panel.

Niña events are similar to the correlation pattern shown in Fig. 7a. Both analyses show the SST anomalies onset at the South American coast and propagate westward along the equator, but the EP-La Niña has much weaker intensity than EP-El Niño. Figures 10c and 10d show that the CP-El Niño and La Niña events look very much alike except with opposite signs. SST anomalies in both phases appear first in the central Pacific and off the coast of North America. Most of the onset activities concentrate in the central Pacific and then extend off equatorward to form a horseshoe pattern centered at the equator near $160^{\circ} \mathrm{W}$. The evolutions occur in the 


\section{EP type of ENSO}

(a) El Niño

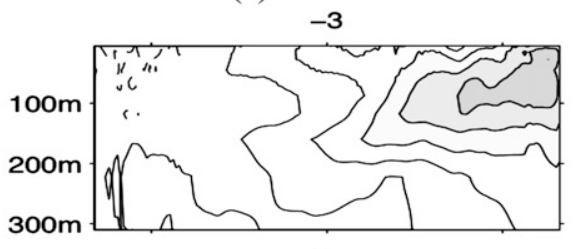

0

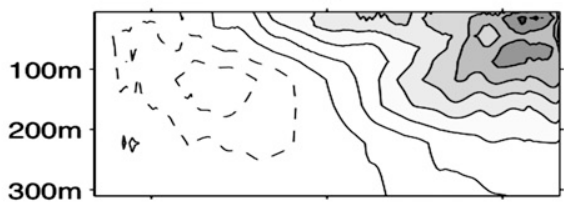

3

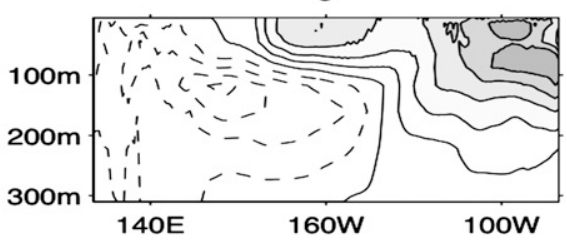

(b) La Niña

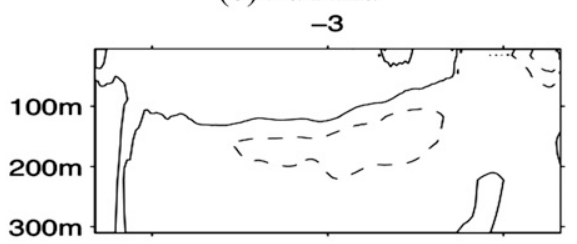

0

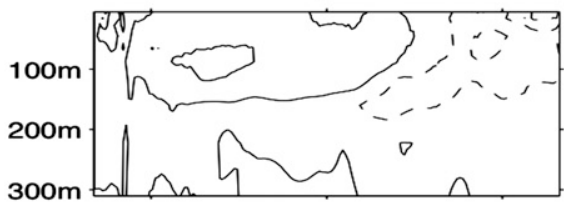

3

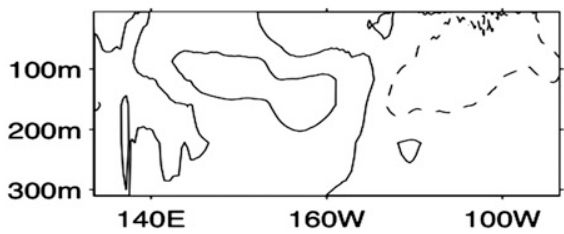

(c) El Niño

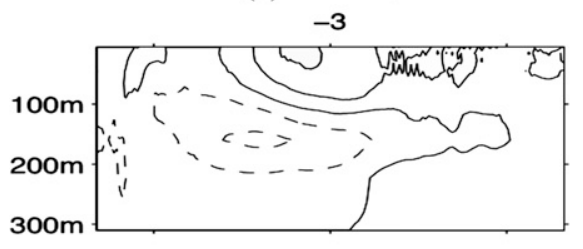

0

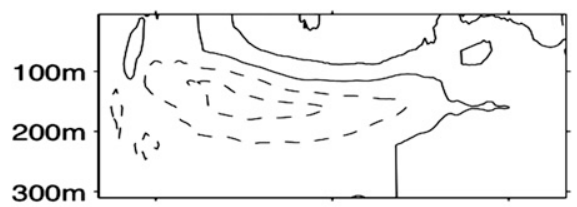

3

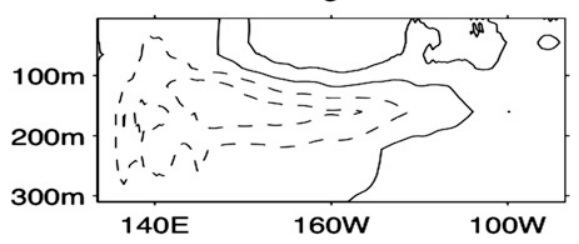

(d) La Niña

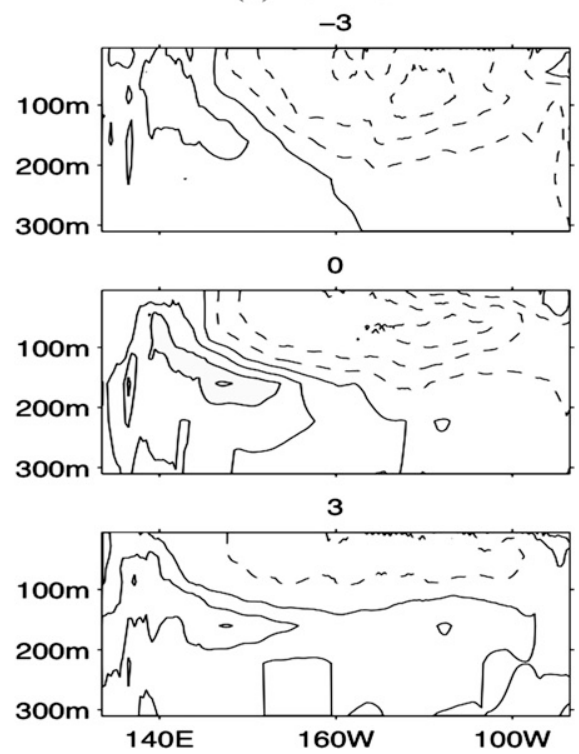

FIG. 11. Composite of subsurface ocean temperature anomalies for (a) EP-El Niño, (b) EP-La Niña, (c) CP-El Niño, and (d) CP-La Niña. Contour intervals are $0.4^{\circ} \mathrm{C}$; negative values are dashed. The lag month referenced to the peak-intensity month is labeled above each panel.

central Pacific without obvious propagation. Overall, the composite SST anomaly patterns shown in Figs. 10c and $10 \mathrm{~d}$ are the same as the correlation pattern shown in Fig. 7b. Figure 11 shows the composites for subsurface temperature anomalies. For EP-El Niño, the composites are similar to the correlation results (Fig. 11a), which shows large and out-of-phase temperature anomalies appearing on both sides of the Pacific basin. The EP-La Niña composite shows weaker subsurface anomalies, but the out-of-phase anomalies and their basinwide propagation can still be identified (Fig. 11b). For the CP events (Figs. 11c and 11d), the warm and cold composites both show a local subsurface temperature evolution rather than a basinwide evolution. 


\section{EP type of ENSO}

(a) El Niño

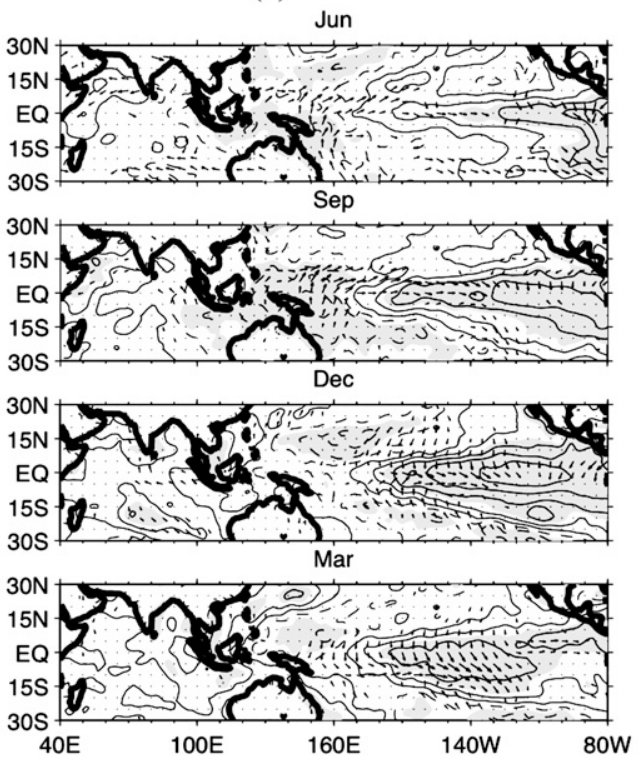

(b) La Niña
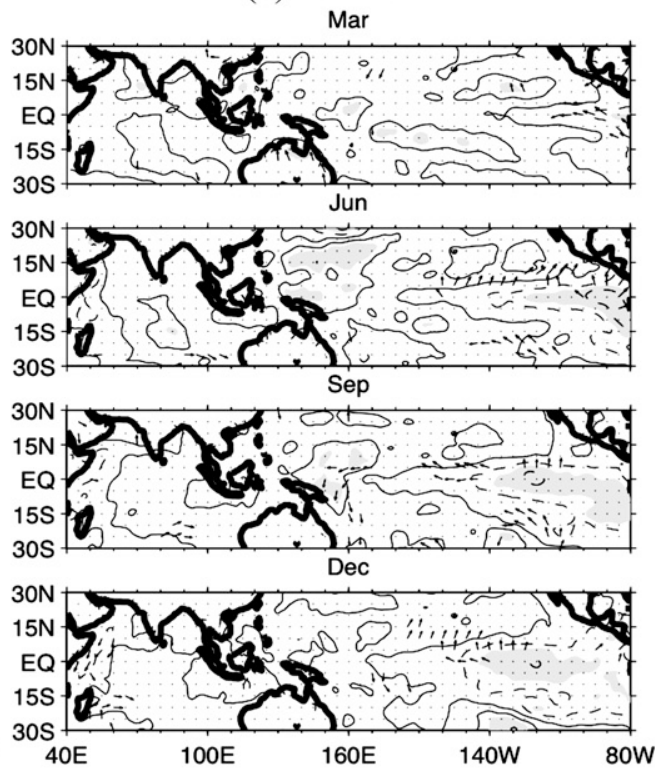

CP type of ENSO

(c) El Niño

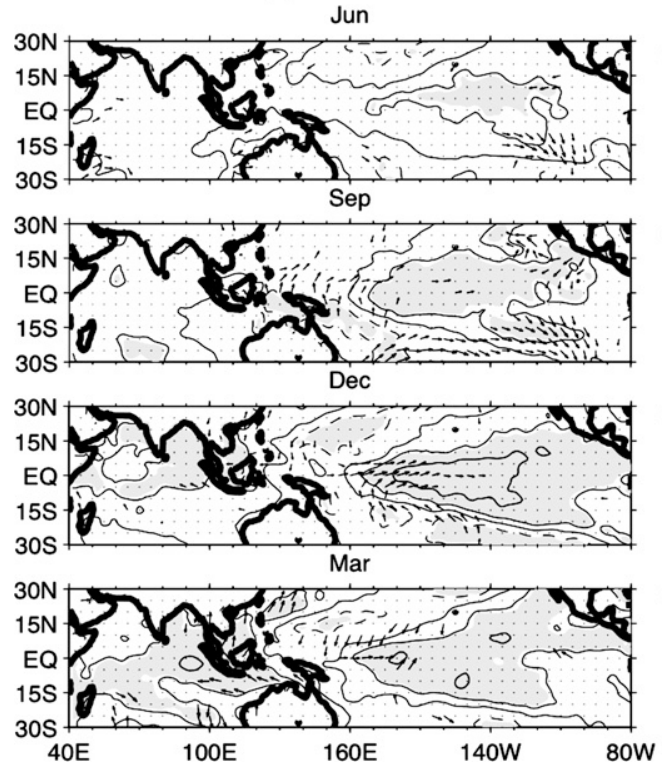

(d) La Niña

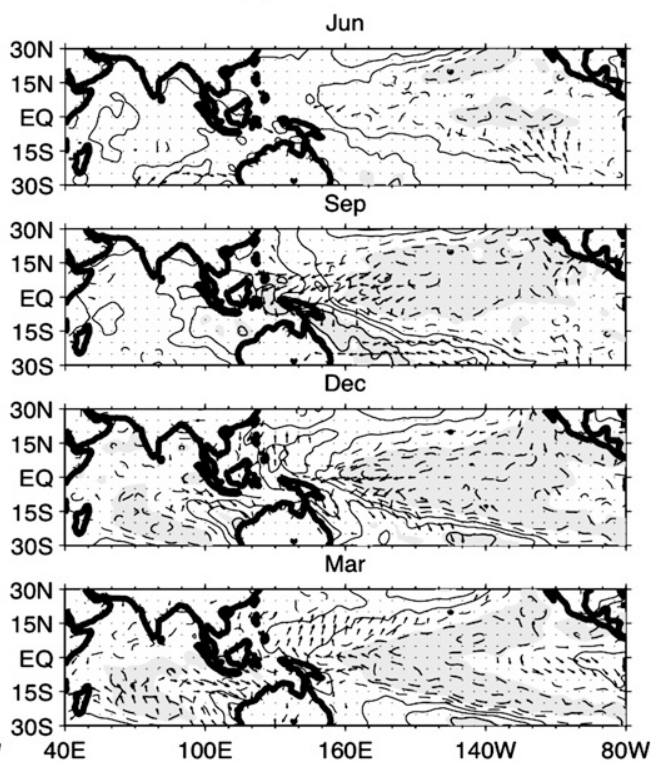

FIG. 12. Composite of SST and surface winds anomalies for (a) EP-El Niño, (b) EP-La Niña, (c) CP-El Niño, and (d) CP-La Niña events referenced to the calendar month. Wind vectors are shown and SST are shaded when they pass the $95 \%$ Student's $t$ significance test.

5. Phase locking to the seasonal cycle and the evolutions of the EP and CP types of ENSO

To identify the phase-locking properties of the EPand CP-ENSO, we also constructed a composite based on calendar months. The composite results are shown in Fig. 12. We include the Indian Ocean region in the analyses to show the ENSO teleconnection in this region. The surface wind and SST anomalies used in this analysis are normalized to highlight the variability in the Indian Ocean, which is generally weaker than in the Pacific. Normalized SST anomalies that are statistically significant at $95 \%$ level are shaded. Figure 12a shows that EP-El Niño is associated with significant wind 
anomalies covering a large part of the tropical Pacific, with the wind converging into the warm SST region. Cold SST anomalies cover the western Pacific and extend into the eastern Indian Ocean and around northern Australia. The southeasterly wind near Sumatra enhances negative SST anomalies during fall and winter, and the northeasterly wind in the Arabian Sea near the coast of Oman enhances positive SST anomalies in the western Arabian Sea during boreal summer to fall. As a result, SST anomalies warm up in the eastern Indian Ocean and cool down in the western Indian Ocean, forming the so-called Indian Ocean dipole (IOD) pattern (Saji et al. 1999; Webster et al. 1999) in boreal fall. After the EP-El Niño reaches its peak phase, the western anomaly center of the IOD spreads eastward and evolves into a basinwide warming. This IOD and Indian Ocean warming sequence is similar to that discussed by An (2004) and Yu and Lau (2004). The composite analyses suggest that the IOD mode has a tendency to appear during EP-El Niño events, but more research is needed to have a better understanding of the linkage between them. We also notice that the EP-El Niño reaches it mature phase during the wintertime. However, in Fig. 12b, most of the features in Fig. 12a are missing, probably because of the weak intensity of EPLa Niña events. Note that the composites shown in Fig. $12 \mathrm{~b}$ are not at the same calendar months as in Fig. 12a. They are selected to better display the evolution of these two phases of the EP events.

Figures $12 \mathrm{c}$ and $12 \mathrm{~d}$ are the composite for CP-El Niño and La Niña events. The warm and cold composites basically show similar patterns with reversed signs. The wind and SST anomaly patterns are confined mostly in the central Pacific during the CP events, suggesting that CP-ENSO is a local air-sea coupling phenomenon. Both CP-El Niño and La Niña events are found to reach their mature phases during wintertime. During the decaying phase (from winter to spring) of the warm and cold CP events, surface wind anomalies in the southeastern Indian Ocean tend to rotate counterclockwise and clockwise, respectively. Such wind pattern leads to the positive SST anomalies to its east and negative SST anomalies to its west for the CP-La Niña events and assume a subtropical dipole mode in the southern Indian Ocean. Although not as obvious for CP-El Niño, we can still find positive SST anomalies in the western Indian Ocean and negative SST anomalies in the eastern Indian Ocean (although not significant) that together assume a subtropical dipole mode with opposite signs around $10^{\circ}-30^{\circ} \mathrm{S}$. This SST anomaly pattern is similar to the regression of Indian Ocean SST and ENSO index in February and March identified by Xie et al. (2002). The surface wind anomaly patterns shown in our Figs. $12 \mathrm{c}$ and $12 \mathrm{~d}$ are similar to the wind stress anomalies that they obtained for the southern Indian Ocean SST variability (see their Fig. 14a). Figure 12 implies that the EP-type events are more effective in establishing the teleconnection between the $\mathrm{El}$ Niño and the tropical Indian Ocean, while the CP-type events influencing the southern Indian Ocean SST more.

To further understand the onset and decay of the EP and CP types of ENSO, composite Niño SST indices for the El Niño and La Niña phases of these two ENSO types are examined in Fig. 13. Here, the positive and negative $0.5^{\circ} \mathrm{C}$ (the dashed lines in the figure) are used to define the onset and termination of ENSO. In the figure, the composite Niño indices for the La Niña phases are reversed in sign for the sake of comparison with the El Niño phases. Figures 13a-d show the onset of the EP-El Niño appears from the Niño1+2 region in March, then the Niño-3 region in April, the Niño-3.4 region in May, and the Niño-4 region in Septemberestablishing a westward propagation. This type of El Niño reaches its mature phase in the boreal winter. All the Niño indices decay near April of the second year, except for the Niño1+2 index, which decays later in July of the second year. As for EP type of La Niña, the amplitude is much weaker than the EP-El Niño and is difficult to define its onset time based on the $0.5^{\circ} \mathrm{C}$ criteria. Nevertheless, it is obvious from the figure that the first time all four Niño indices cross the zero line (i.e., change sign) occurs at about the same as the composites for the EP type of El Niño. The EP-La Niña grows at a much slower rate than the EP-El Niño, but both reach their peak intensity around the same time. For the EP-La Niña, the composite Niño SST anomalies decay earlier than those for the EP-El Niño, likely a result of the weaker intensity of the EP-La Niña. Besides the weaker intensity and shorter duration, Figs. 13a-d indicate the EP type of La Niña has a life cycle similar to that of the EP type of El Niño.

Figures $13 \mathrm{e}-\mathrm{h}$ show the composites for the warm and cold phases of the CP-ENSO. Both El Niño and La Niña phases show very similar evolution in all four Niño index regions. They tend to onset in summer, reach their peak intensity around December-January, and decay in early spring of the second year. No obvious propagation is seen in the onset, developing, or decaying timing. The CP type of El Niño and La Niña share a very similar life cycle, and it is reasonable to believe that they are driven by a similar underlying mechanism. It should be noted that the duration of the CP-ENSO is about 8 months-shorter than the duration of the EP type of El Niño, which is about 15 months. 
EP ENSO
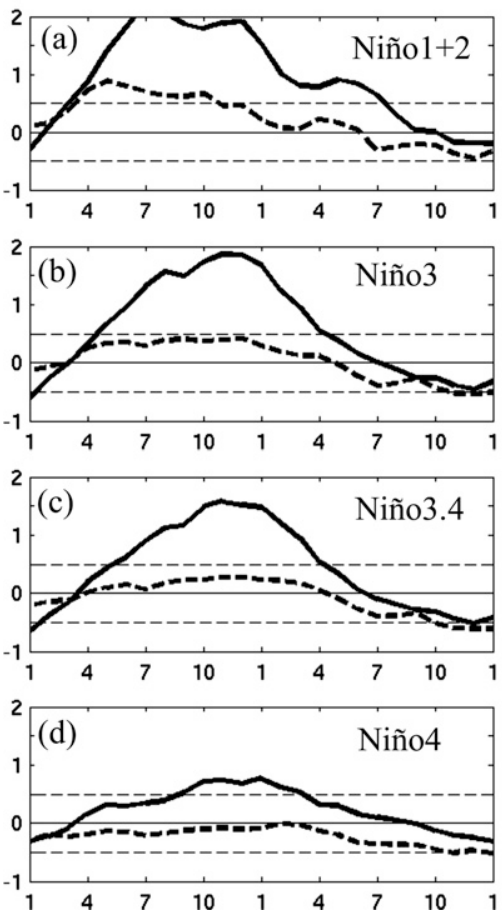

CP ENSO
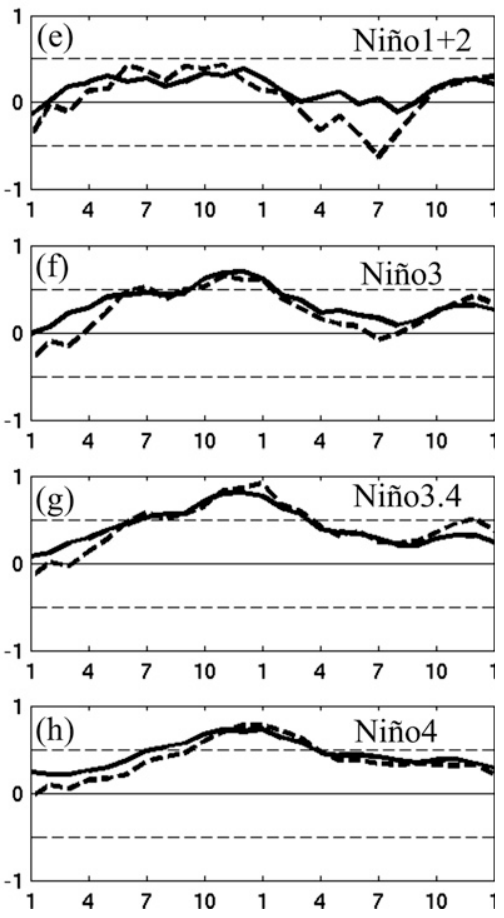

FIG. 13. Composite Niño SST indices for the warm (solid) and cold (dashed) phases of the EP- and CP-ENSO referenced to the calendar months. (a) Niño1+2, (b) Niño-3, (c) Niño-3.4, and (d) Niño-4 for the EP-ENSO. (e) Niño1+2, (f) Niño-3, (g) Niño-3.4, and (h) Niño-4 for the CP-ENSO. Dashed lines denote the $\pm 0.5^{\circ} \mathrm{C}$ criterion to define the onset and decay time. Units are ${ }^{\circ} \mathrm{C}$ in the $y$ axis, and the numbers on the $x$ axis denote the calendar months.

The Niño-3.4 SST index is widely used to identify El Niño and La Niña events. However, it is not the best way to capture the EP- and CP-ENSO as shown in Fig. 13. Besides, Trenberth and Stepaniak (2001) pointed out that Niño-3.4 could not distinguish canonical El Niño and the El Niño happening in the central Pacific. In Fig. 14, we identify the months of EP and CP events based on the principal components of the two leading EOFs. When the PC values pass one standard deviation, we identify those months as parts of EP or CP events. All of the identified event months are marked on the time series of Niño-3.4 smoothed with a 3-month running mean. Figure 14a shows how EP-El Niño and La Niña events are projected onto the Niño-3.4 index. The red and blue squares indicate the warm and cold EP events, respectively. Generally, Niño-3.4 can capture most EP-El Niño events, but not EP-La Niña events. Corresponding to the EP-El Niño months, the Niño-3.4 index also shows large values. The EP-El Niño events (the red squares) are projected around most of the peak phases of the Niño-3.4 time series, for example around the 1971-72, 1982-83, and 1997-98 El Niño events. However, the valleys of the Niño-3.4 time series hardly capture any of the EP-La Niña events (the blue squares). It is because EP-La Niñas, in general, have weak intensities and cannot spread their SST anomalies into the Niño-3.4 region. Figure 13b shows the same Niño-3.4 time series with CP-El Niño and La Niña events marked respectively as red and blue circles. The Niño-3.4 index corresponds well to the activity of the CP-ENSO. Major CP-La Niña events (blue circles) are projected well to the valleys of the Niño-3.4 time series. CP-El Niño events (red circles) are projected to the weak El Niño events defined by the Niño-3.4 index. It is noticed that the many of the El Niño events after the 1980s appears as the CP type of El Niño. Consistent with the suggestion of Trenberth and Stepaniak (2001), the Niño-3.4 SST index is able to represent the general temperature variations in the equatorial Pacific, but it is not able to separate the EP and CP types. New ENSO indices that can better describe and separate these two types of ENSO events are needed.

\section{Conclusions and discussion}

Two different types of ENSO are described and contrasted in this paper according to their spatial structure: one centers in the eastern Pacific and the other in the 
(a)

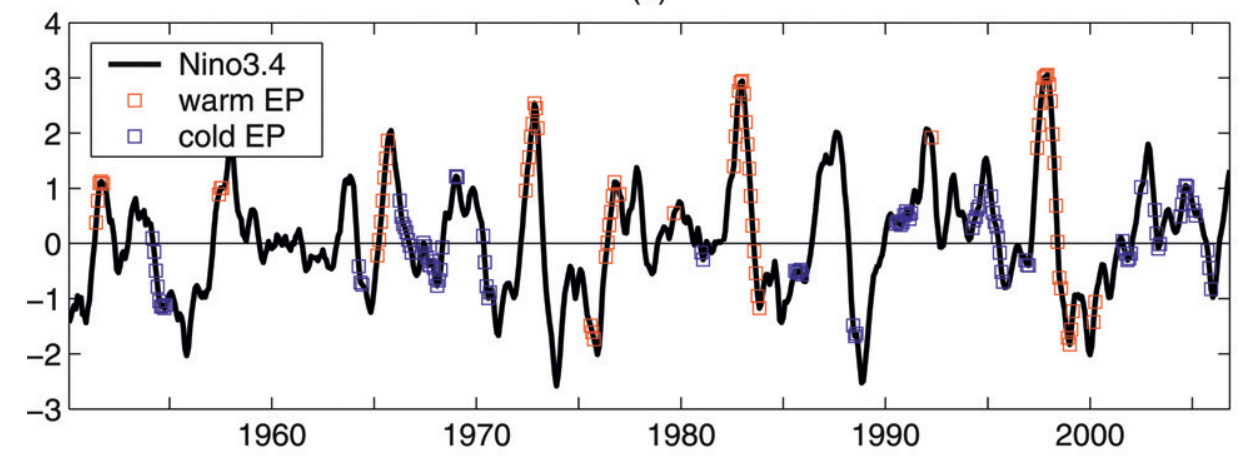

(b)

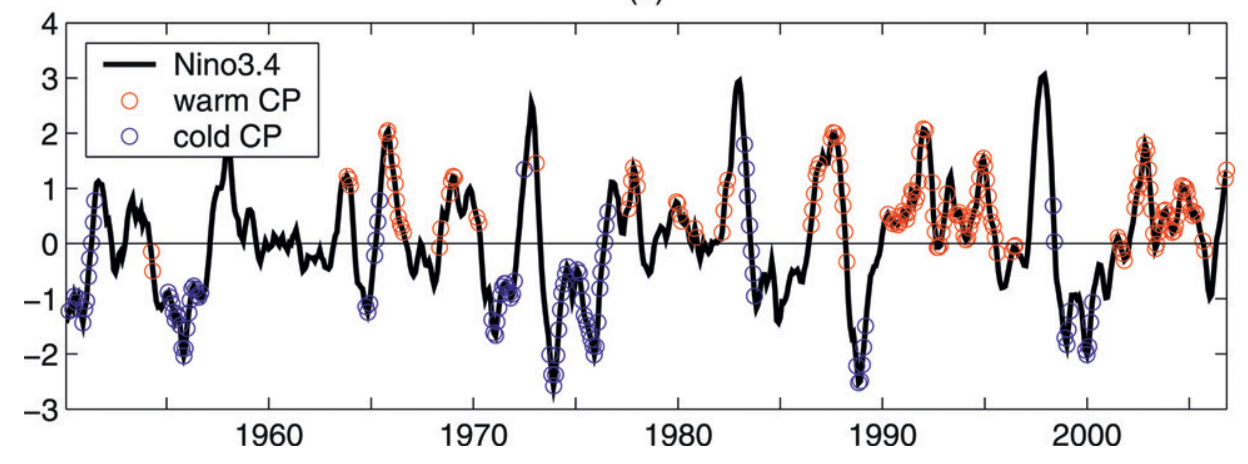

FIG. 14. Time series of Niño-3.4 SST index marked with the months of (a) EP-El Niño and La Niña events and (b) CP-El Niño and La Niña events defined by the principal components from Fig. 3.

central Pacific. Composite analysis and hierarchical cluster analysis are applied to identify the positive and negative phase of these two SST anomaly structures. The EP-ENSO is closer to the canonical ENSO and fits very well with the evolution described by the delayedoscillator theory of ENSO. This type of ENSO appears to be a basinwide coupling phenomenon, which relies on thermocline variations for its generation and phase reversal. The CP type of ENSO has most of its major SST, surface wind, and subsurface ocean variations in the central equatorial Pacific. This type involves only a shallow layer (about $100 \mathrm{~m}$ ) of subsurface ocean temperature variations. Since this ENSO type starts its development from surface, it is likely that local atmospheric forcing is important to this type of ENSO, such as those associated with the Madden-Julian oscillation (Madden and Julian 1971) and Asian or Australian monsoons. It is noticed that the CP-ENSO does not have a phase-reversal feature in its evolution, while such a feature can be identified for the EP-ENSO. These two ENSO types also exhibit different teleconnection with the Indian Ocean, with the EP-ENSO linked more closely with the tropical Indian Ocean whereas the CP-ENSO is linked more with the southern Indian Ocean.
From the composite analysis, we further prove that the warm and cold phases of CP-ENSO tend to have similar physical characteristics and similar patterns. They show similar evolution and phase-locking features, implying that CP type of El Niño and La Niña should share a common physical process. The difference between warm and cold phases of EP-ENSO could be the result of either stronger or weaker intensity. Otherwise, EP types of El Niño and La Niña basically have similar patterns and evolution. The weaker strength of EP-La Niña compared to EP-El Niño could be a result of the subsurface ocean distribution. As suggested in Rodgers et al. (2004), the cold water in the eastern equatorial Pacific generally comes from upwelling, and the temperature of cold water below the thermocline is not much different from the SST in the cold tongue region. Thus, the negative SST anomalies are limited by the weak vertical temperature gradient in the eastern tropical Pacific. On the other hand, the warm SST anomalies usually come from the warm pool region, where SST is much warmer than in the cold tongue region. As a result, the El Niño in the cold tongue region tends to have greater intensity than the La Niña in the same region.

Our results point out the possibility that there may be 
more than one type of ENSO in the tropical Pacific. A similar idea was recently suggested by Ashok et al. (2007). We found the PC time series of our CP-ENSO has a high correlation (a correlation coefficient of 0.82 ) with the so-called El Niño Modoki index that they define to identify the noncanonical ENSO events. Their index was based on the difference between SST anomalies in the central equatorial Pacific and those in the eastern and western Pacific. Nevertheless, more analyses are needed to better identify the underlying dynamics of these two types of ENSO and to determine for sure if they are different modes of interannual tropical variability. The possibility exits that they may be related to nonlinear properties of the same ENSO dynamics. As elaborated in several recent studies (e.g., Rodgers et al. 2004; An and Jin 2004; Schopf and Burgman 2006), the nonlinearity can lead to spatial asymmetry between the El Niño and La Niña phases of ENSO. Also, as suggested by Harrison and Schopf (1984), ENSO SST anomalies could appear in the central or eastern Pacific related to the season of Kelvin wave propagation. Our results of different onset time for the EP- and CP-ENSO could be related to their argument. The results presented in this paper suggest that there is a need to define new ENSO indices to better monitor the different types of ENSO activity.

Acknowledgments. The authors thank Dr. Clara Deser, Dr. Jerry Meehl, and two anonymous reviewers for their useful comments, which have improved this paper. The authors benefited from the discussions with Dr. Tong Lee of JPL and Dr. Kuo-lin Hsu of University of California, Irvine. This research was supported by NASA (NNX06AF49H), NSF (ATM-0638432), and JPL (Subcontract No.1290687). Data analyses were performed at University of California, Irvine's Earth System Modeling Facility and the San Diego Supercomputer Center. The GECCO data is downloaded from http://www.ecco-group.org/products.htm, and the HadISST data is downloaded from http://hadobs. metoffice.com/hadisst/data/download.html.

\section{REFERENCES}

Adler, R. F., and Coauthors, 2003: The version-2 global precipitation climatology project (GPCP) monthly precipitation analysis (1979-present). J. Hydrometeor., 4, 1147-1167.

An, S. I., 2004: A dynamic link between the basin-scale and zonal modes in the tropical Indian Ocean. Theor. Appl. Climatol., 78, 203-215.

- and B. Wang, 2000: Interdecadal change of the structure of the ENSO mode and its impact on the ENSO frequency. $J$. Climate, 13, 2044-2055.

_ and F. F. Jin, 2004: Nonlinearity and asymmetry of ENSO. J. Climate, 17, 2399-2412.
Ashok, K., S. K. Behera, S. A. Rao, H. Weng, and T. Yamagata, 2007: El Niño Modoki and its possible teleconnection. J. Geophys. Res., 112, C11007, doi:10.1029/2006JC003798.

Barnett, T., M. Latif, E. Kirk, and E. Roeckner, 1991: On ENSO physics. J. Climate, 4, 487-515.

Battisti, D. S., and A. C. Hirst, 1989: Interannual variability in a tropical atmosphere-ocean model: Influence of the basic state, ocean geometry and nonlinearity. J. Atmos. Sci., 46, $1687-1712$.

Cheng, X., and J. M. Wallace, 1993: Cluster analysis of the Northern Hemisphere wintertime 500-hPa height field: Spatial patterns. J. Atmos. Sci., 50, 2674-2696.

Enfield, D. B., and L. Cid S., 1991: Low-frequency changes in El Niño-Southern Oscillation. J. Climate, 4, 1137-1146.

Fovell, R. G., and M. Y. C. Fovell, 1993: Climate zones of the conterminous United States defined using cluster analysis. J. Climate, 6, 2103-2135.

Fu, C., H. Diaz, and J. Fletcher, 1986: Characteristics of the response of sea surface temperature in the central Pacific associated with warm episodes of the Southern Oscillation. Mon. Wea. Rev., 114, 1716-1739.

Harrison, D., and P. S. Schopf, 1984: Kelvin-wave-induced anomalous advection and the onset of surface warming in El Niño events. Mon. Wea. Rev., 112, 923-933.

Hsieh, W. W., 2004: Nonlinear multivariate and time series analysis by neural network methods. Rev. Geophys., 42, RG1003, doi:10.1029/2002RG000112.

Jin, F. F., and J. D. Neelin, 1993a: Modes of interannual tropical ocean-atmosphere interaction-A unified view. Part I: Numerical results. J. Atmos. Sci., 50, 3477-3503.

_ , and D. Neelin, 1993b: Modes of interannual tropical oceanatmosphere interaction-A unified view. Part III: Analytical results in fully coupled cases. J. Atmos. Sci., 50, 3523-3540.

Kalnay, E., and Coauthors, 1996: The NCEP/NCAR 40-Year Reanalysis Project. Bull. Amer. Meteor. Soc., 77, 437-471.

Kessler, W. S., 2002: Is ENSO a cycle or a series of events? Geophys. Res. Lett., 29, 2125, doi:10.1029/2002GL015924.

Kõhl, A., D. Dommenget, K. Ueyoshi, and D. Stammer, 2006: The Global ECCO 1952 to 2001 Ocean Synthesis. Tech. Rep. 40, $43 \mathrm{pp}$. [Available online at http://www.ecco-group.org/ecco1/ report/report_40.pdf.]

Larkin, N. K., and D. E. Harrison, 2005: Global seasonal temperature and precipitation anomalies during El Niño autumn and winter. Geophys. Res. Lett., 32, L16705, doi:10.1029/ 2005 GL022860.

Madden, R. A., and P. R. Julian, 1971: Detection of a 40-50 day oscillation in the zonal wind in the tropical Pacific. J. Atmos. Sci., 28, 702-708.

Mantua, N. J., S. R. Hare, Y. Zhang, J. M. Wallace, and R. C. Francis, 1997: A Pacific interdecadal climate oscillation with impacts on salmon production. Bull. Amer. Meteor. Soc., 78, 1069-1079.

Monahan, A. H., 2001: Nonlinear principal component analysis: Tropical Indo-Pacific sea surface temperature and sea level pressure. J. Climate, 14, 219-233.

Neelin, J. D., 1991: The slow sea surface temperature mode and the fast-wave limit: Analytic theory for tropical interannual oscillations and experiments in a hybrid coupled model. $J$. Atmos. Sci., 48, 584-606.

Rasmusson, E. M., and T. H. Carpenter, 1982: Variations in tropical sea surface temperature and surface wind fields associated with the Southern Oscillation/El Niño. Mon. Wea. Rev., 110, 354-384. 
Rayner, N. A., D. E. Parker, E. B. Horton, C. K. Folland, L. V. Alexander, D. P. Rowell, E. C. Kent, and A. Kaplan, 2003: Global analyses of sea surface temperature, sea ice, and night marine air temperature since the late nineteenth century. $J$. Geophys. Res., 108, 4407, doi:10.1029/2002JD002670.

Rodgers, K. B., P. Friederichs, and M. Latif, 2004: Tropical Pacific decadal variability and its relation to decadal modulations of ENSO. J. Climate, 17, 3761-3774.

Saji, N. H., B. N. Goswami, P. N. Vinayachandran, and T. Yamagata, 1999: A dipole mode in the tropical Indian Ocean. $\mathrm{Na}$ ture, 401, 360-363.

Schopf, P. S., and M. J. Suarez, 1988: Vacillations in a coupled ocean-atmosphere model. J. Atmos. Sci., 45, 549-566.

— residuals and asymmetry. J. Climate, 19, 3167-3179.

Suarez, M. J., and P. S. Schopf, 1988: A delayed action oscillator for ENSO. J. Atmos. Sci., 45, 3283-3287.

Trenberth, K. E., and D. P. Stepaniak, 2001: Indices of El Niño evolution. J. Climate, 14, 1697-1701.

— the tropics: Different flavors of El Niño. J. Climate, 19, 49564973.

Wang, B., 1995: Interdecadal changes in El Niño onset in the last four decades. J. Climate, 8, 267-285.

Ward, J. H., 1963: Hierarchical grouping to optimize an objective function. J. Amer. Stat. Assoc., 58, 236-244.

Webster, P. J., A. M. Moore, J. P. Loschnigg, and R. R. Leben,
1999: Coupled ocean-atmosphere dynamics in the Indian Ocean during 1997-98. Nature, 401, 356-360.

Wolter, K., 1987: The Southern Oscillation in surface circulation and climate over the tropical Atlantic, eastern Pacific, and Indian Oceans as captured by cluster analysis. J. Climate Appl. Meteor., 26, 540-558.

Xie, S. P., H. Annamalai, F. A. Schott, and J. P. McCreary, 2002: Structure and mechanisms of south Indian Ocean climate variability. J. Climate, 15, 864-878.

$\mathrm{Xu}$, J., and J. C. L. Chan, 2001: The role of the Asian-Australian monsoon system in the onset time of El Niño events. J. Climate, 14, 418-433.

Yasunari, T., 1985: Zonally propagating modes of the global eastwest circulation associated with the Southern Oscillation J. Meteor. Soc. Japan, 63, 1013-1029.

Yu, J.-Y., and K. M. Lau, 2004: Contrasting Indian Ocean SST variability with and without ENSO influence: A coupled atmosphere-ocean GCM study. Meteor. Atmos. Phys., 90, 179191, doi:10.1007/s00703-004-0094-7.

_ barrier in SST and ocean heat content indices: 1958-2001. J. Geophys. Res., 112, D13106, doi:10.1029/2006JD007654.

Zhang, X., J. Sheng, and A. Shabbar, 1998: Modes of interannual and interdecadal variability of Pacific SST. J. Climate, 11, 2556-2569.

Zhang, Y., J. M. Wallace, and D. S. Battisti, 1997: ENSO-like interdecadal variability: 1900-93. J. Climate, 10, 1004-1020. 